\title{
Gersemiols A-C and Eunicellol A, Diterpenoids from the Arctic Soft Coral Gersemia fruticosa
}

Carlos Angulo-Preckler, ${ }^{+*}$ * Grégory Genta-Jouve, ${ }^{\ddagger}$ Nipun Mahajan, ${ }^{\S}$ Mercedes de la Cruz, ${ }^{\perp}$ Nuria de Pedro, ${ }^{\perp}$ Fernando Reyes, ${ }^{\perp}$ Katrin Iken, ${ }^{\|}$Conxita Avila, + and Olivier P. Thomas ${ }^{\delta, ~}{ }_{1} *$

† University of Barcelona, Department of Animal Biology (Invertebrates), Faculty of Biology, Av. Diagonal 643 (08028) \& Biodiversity Research Institute (IrBIO) Barcelona, Catalonia, Spain ‡ Université Paris Descartes, Laboratoire de Pharmacognosie et de Chimie des Substances Naturelle, COMETE UMR 8638 CNRS, Paris, France

$\S$ National University of Ireland Galway, Marine Biodiscovery, School of Chemistry, Marine Biodiscovery, National University of Ireland Galway, University Road, Galway, Ireland

$\perp$ Fundación MEDINA, Centro de Excelencia en Investigación de Medicamentos Innovadores en Andalucía, Avda. del Conocimiento 34, Parque Tecnológico de Ciencias de la Salud, E-18016, Armilla, Granada, Spain

|| University of Alaska Fairbanks, School of Fisheries and Ocean Science, Fairbanks AK 99775, USA

$\nabla$ Geoazur, UMR Université Nice Sophia Antipolis-CNRS-IRD-OCA, 250 rue Albert Einstein, 06560 Valbonne, France 
P3 (+)-HRESIMS analyses of $\mathbf{1}$ and $\mathbf{2}$

P4 (+)-HRESIMS analyses of $\mathbf{3}$ and $\mathbf{4}$

P5 ${ }^{1} \mathrm{H}$ NMR spectrum of 1 at $500 \mathrm{MHz}$ in $\mathrm{CDCl}_{3}$

P6 COSY NMR spectrum of 1 at $500 \mathrm{MHz}^{\text {in } \mathrm{CDCl}_{3}}$

P7 NOESY NMR spectrum of 1 at $500 \mathrm{MHz}$ in $\mathrm{CDCl}_{3}$

P8 ${ }^{13} \mathrm{C}$ NMR spectrum of 1 at $125 \mathrm{MHz}$ in $\mathrm{CDCl}_{3}$

P9 HSQC NMR spectrum of 1 at $500 \mathrm{MHz}^{\text {in } \mathrm{CDCl}_{3}}$

P10 Expansion of HSQC NMR spectrum of 1 at $500 \mathrm{MHz}^{\text {in } \mathrm{CDCl}_{3}}$

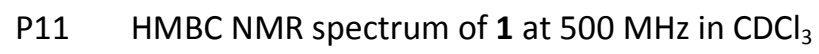

P12 Expansion of $\mathrm{HMBC}$ NMR spectrum of 1 at $500 \mathrm{MHz}$ in $\mathrm{CDCl}_{3}$

$\mathrm{P} 13{ }^{1} \mathrm{H}$ NMR spectrum of 2 at $500 \mathrm{MHz}$ in $\mathrm{CDCl}_{3}$

P14 COSY NMR spectrum of 2 at $500 \mathrm{MHz}$ in $\mathrm{CDCl}_{3}$

P15 ${ }^{13} \mathrm{C}$ NMR spectrum of 2 at $125 \mathrm{MHz}$ in $\mathrm{CDCl}_{3}$

P16 HSQC NMR spectrum of 2 at $500 \mathrm{MHz}^{\text {in } \mathrm{CDCl}_{3}}$

$\mathrm{P} 17 \mathrm{HMBC}$ NMR spectrum of $\mathbf{2}$ at $500 \mathrm{MHz}^{\text {in } \mathrm{CDCl}_{3}}$

P18 ${ }^{1} \mathrm{H}$ NMR spectrum of 3 at $500 \mathrm{MHz}$ in $\mathrm{CDCl}_{3}$

P19 COSY NMR spectrum of 3 at $500 \mathrm{MHz}$ in $\mathrm{CDCl}_{3}$

P20 NOESY NMR spectrum of 3 at $500 \mathrm{MHz}$ in $\mathrm{CDCl}_{3}$

P21 ${ }^{13} \mathrm{C}$ NMR spectrum of 3 at $125 \mathrm{MHz}$ in $\mathrm{CDCl}_{3}$

P22 HSQC NMR spectrum of 3 at $500 \mathrm{MHz}$ in $\mathrm{CDCl}_{3}$

P23 HMBC NMR spectrum of $\mathbf{3}$ at $500 \mathrm{MHz}^{\text {in } \mathrm{CDCl}_{3}}$

P24 ${ }^{1} \mathrm{H}$ NMR spectrum of 4 at $500 \mathrm{MHz}$ in $\mathrm{CDCl}_{3}$

P25 COSY NMR spectrum of 4 at $500 \mathrm{MHz}^{\text {in } \mathrm{CDCl}_{3}}$

P26 NOESY NMR spectrum of 4 at $500 \mathrm{MHz}^{\text {in } \mathrm{CDCl}_{3}}$

P27 ${ }^{13} \mathrm{C}$ NMR spectrum of 4 at $125 \mathrm{MHz}$ in $\mathrm{CDCl}_{3}$

P28 HSQC NMR spectrum of 4 at $500 \mathrm{MHz}^{\text {in } \mathrm{CDCl}_{3}}$

P29 HMBC NMR spectrum of 4 at $500 \mathrm{MHz}^{\text {in } \mathrm{CDCl}_{3}}$

P20 Computational methods for coupling constants of compounds 1

P31 Computational methods for coupling constants of compounds 4 


\section{UHPLC-QqToF analysis of 1 in (+)-ESI}

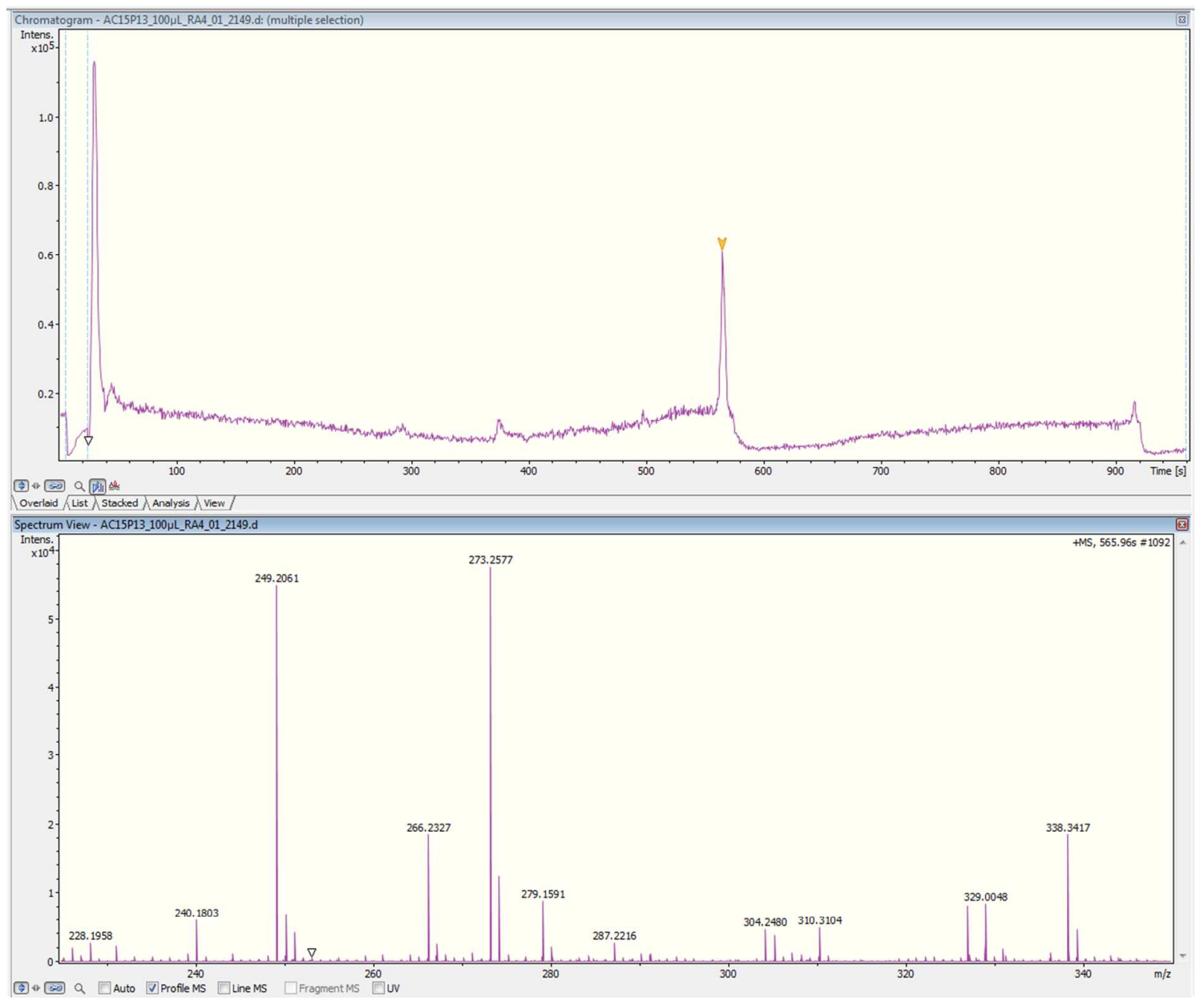

\section{UHPLC-QqToF analysis of 2 in (+)-ESI}

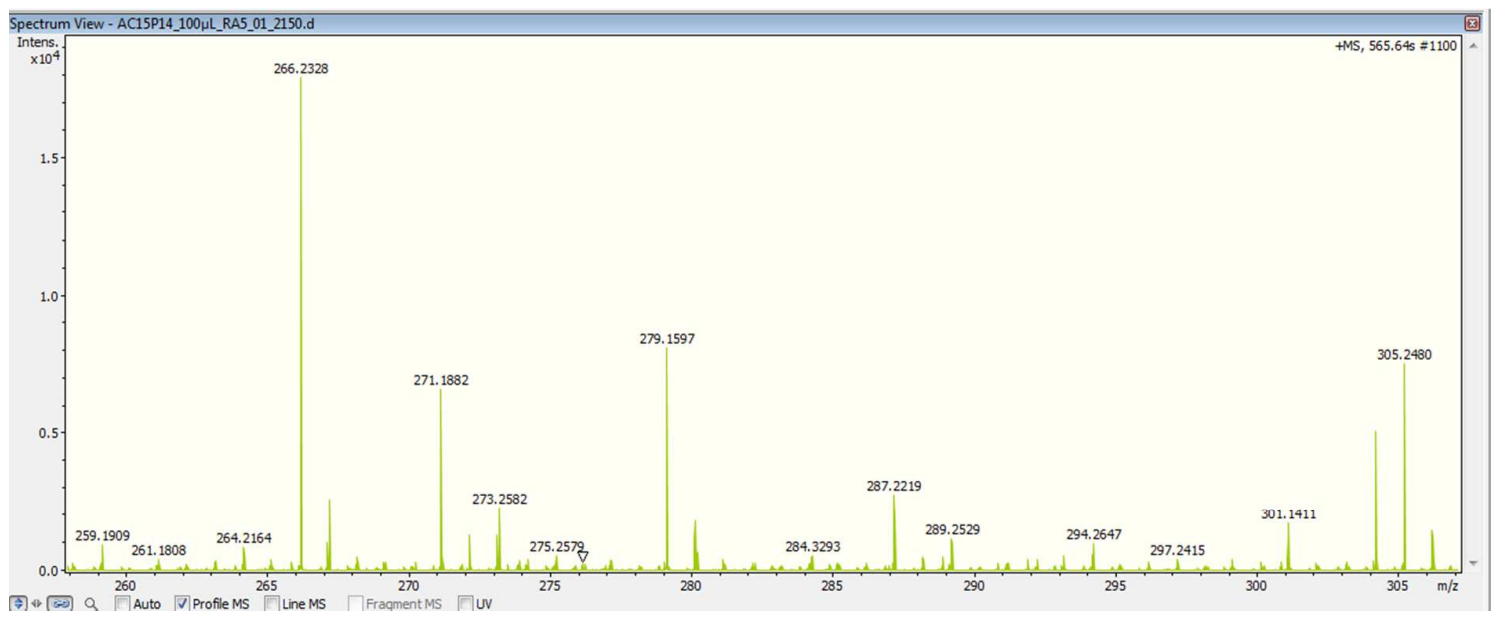


UHPLC-QqToF analysis of 3 in (+)-ESI

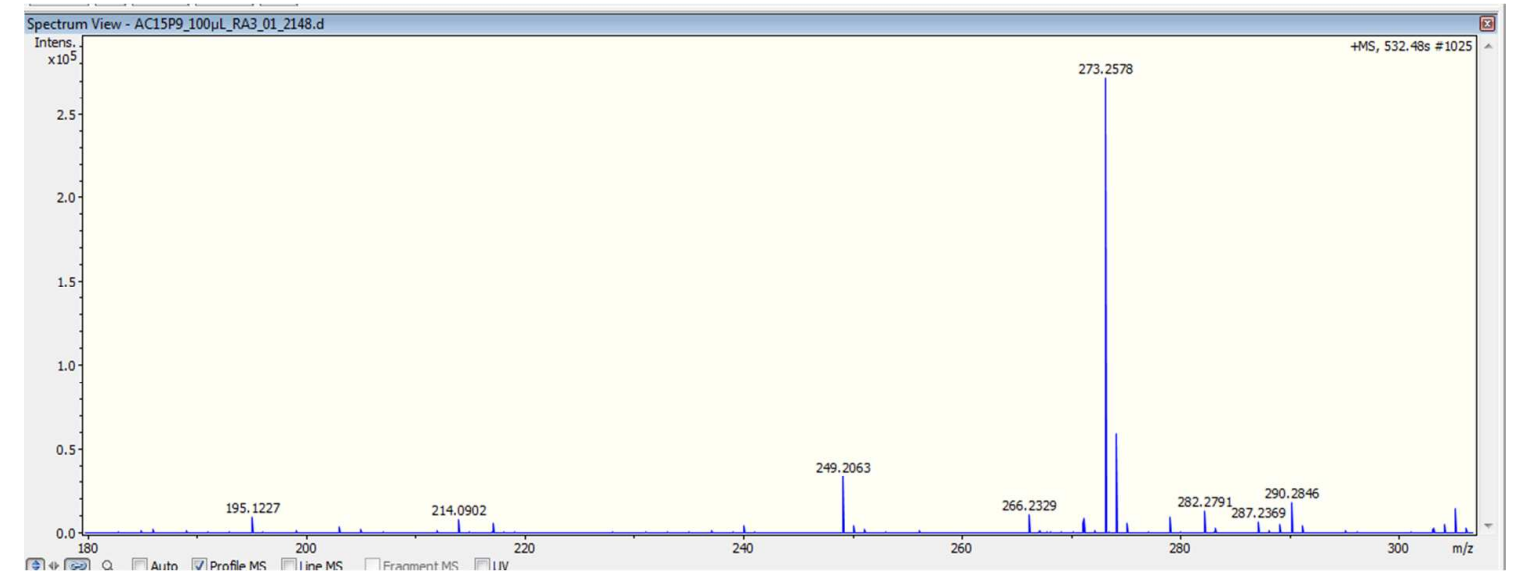

UHPLC-QqToF analysis of 4 in (+)-ESI

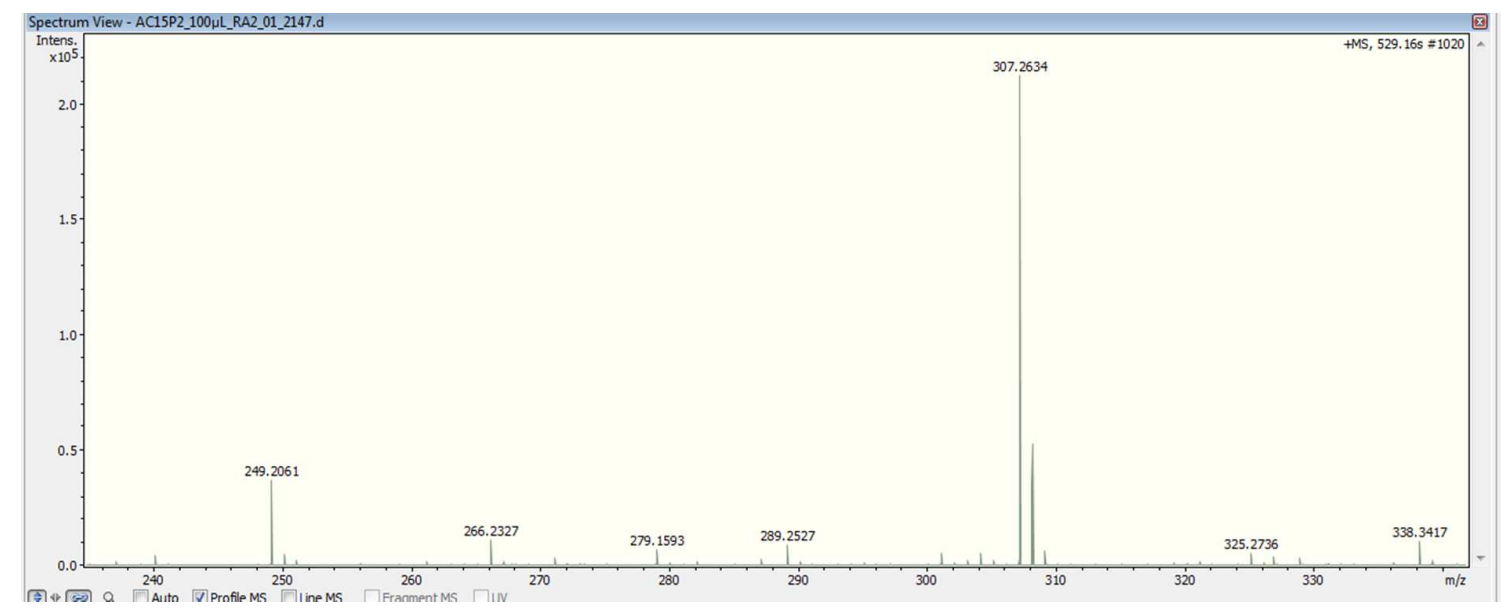




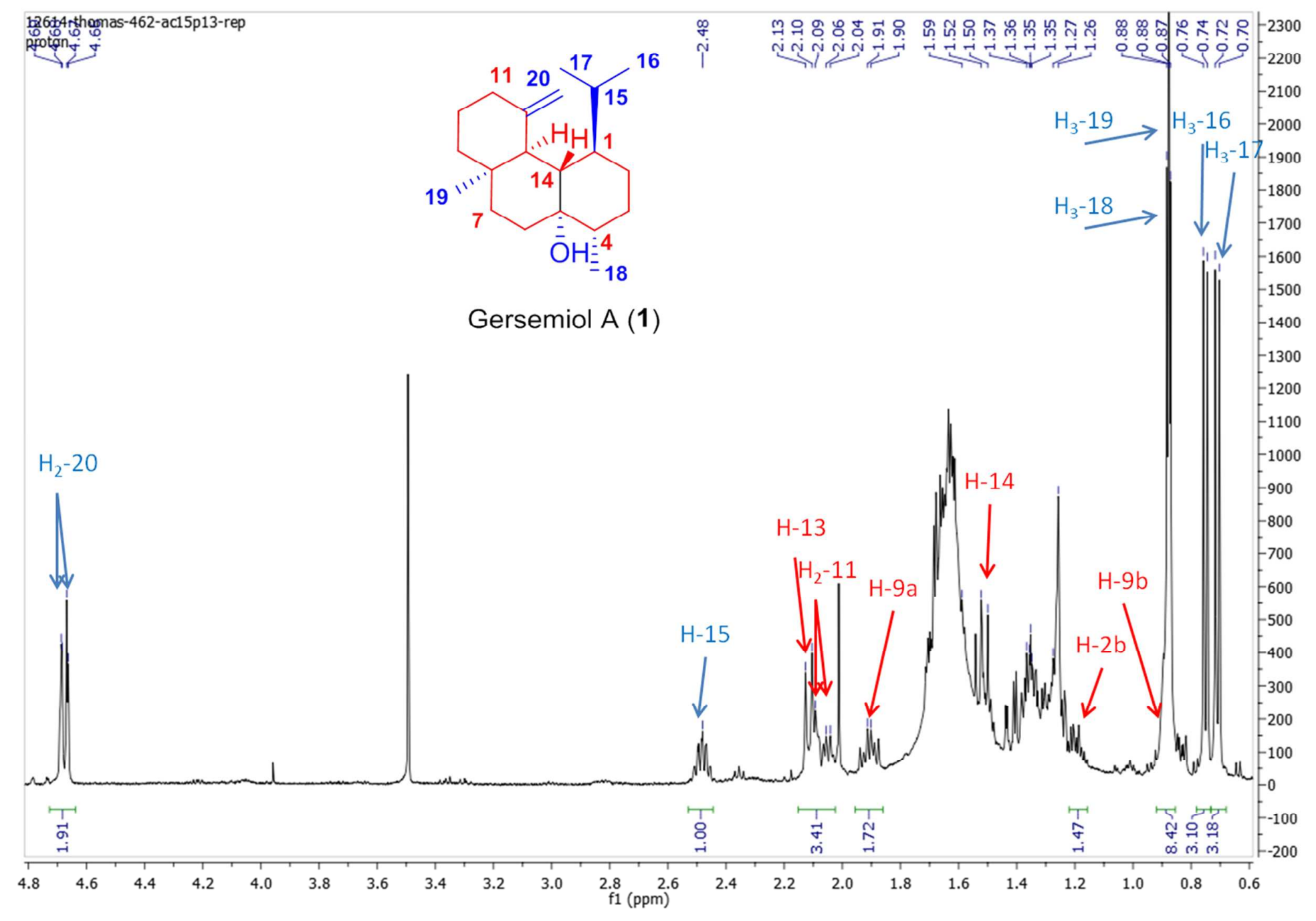

${ }^{1} \mathrm{H}$ NMR spectrum of 1 at $500 \mathrm{MHz}$ in $\mathrm{CDCl}_{3}$ 


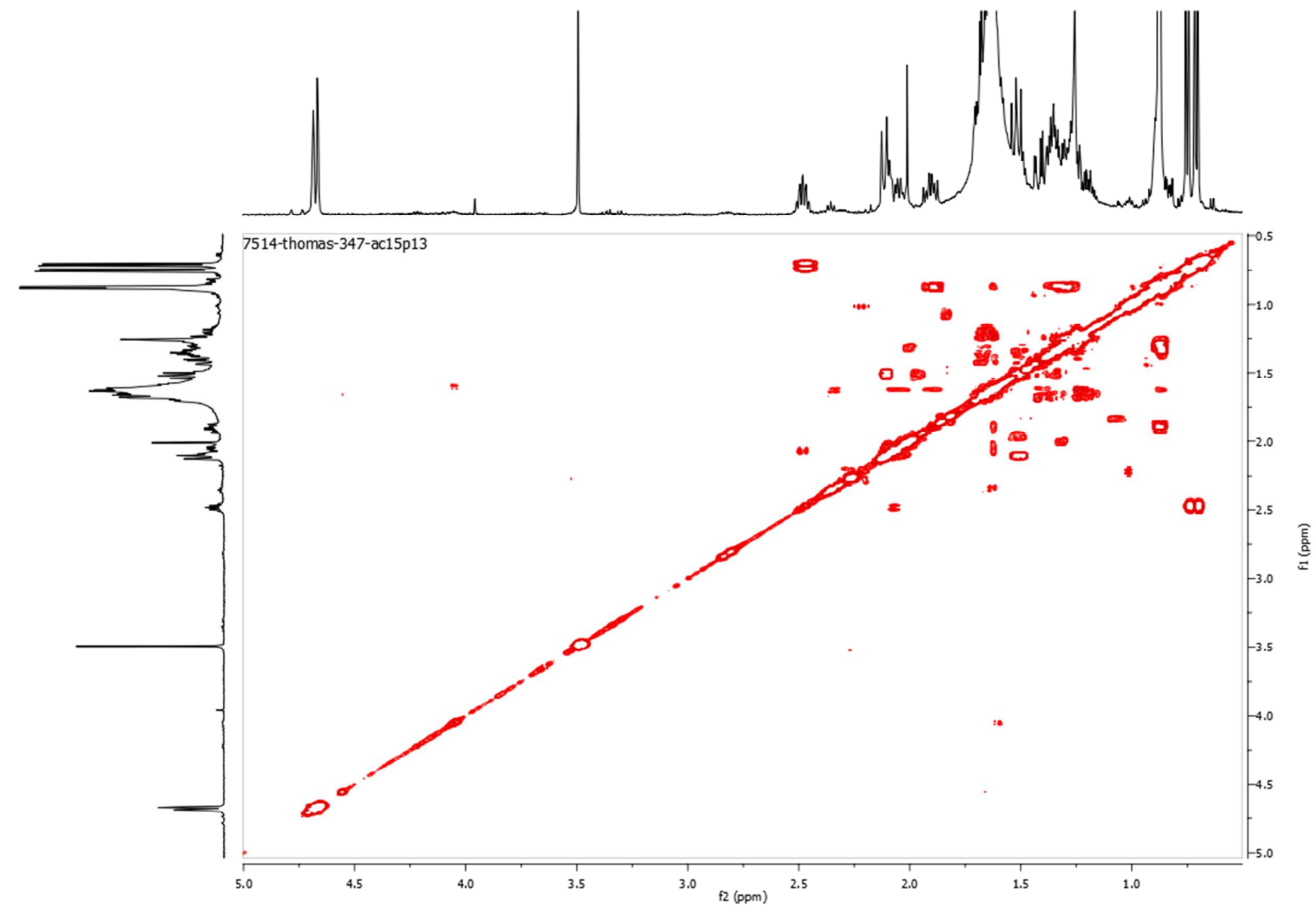

COSY NMR spectrum of 1 at $500 \mathrm{MHz}$ in $\mathrm{CDCl}_{3}$ 


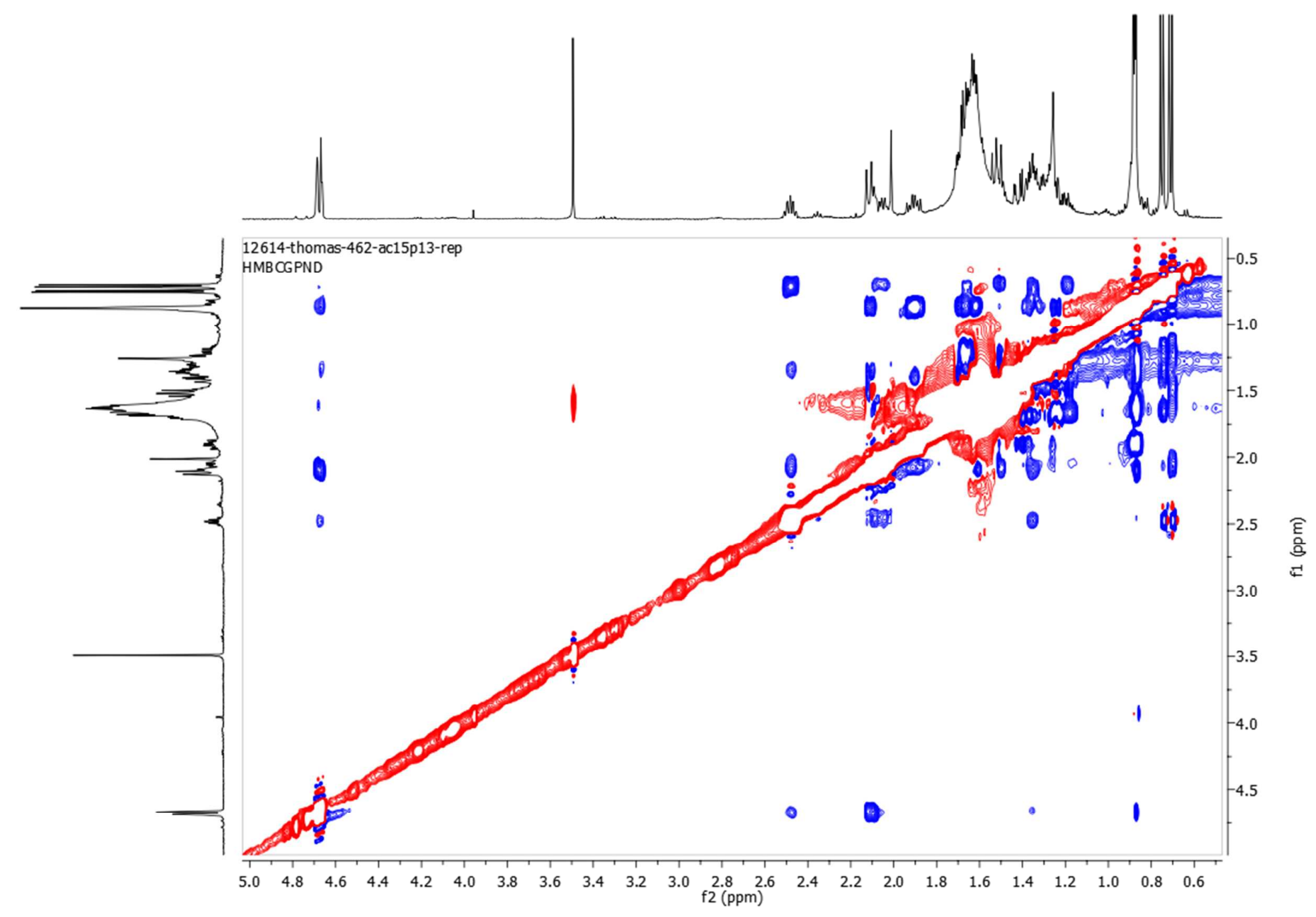

NOESY NMR spectrum of 1 at $500 \mathrm{MHz}$ in $\mathrm{CDCl}_{3}$ 


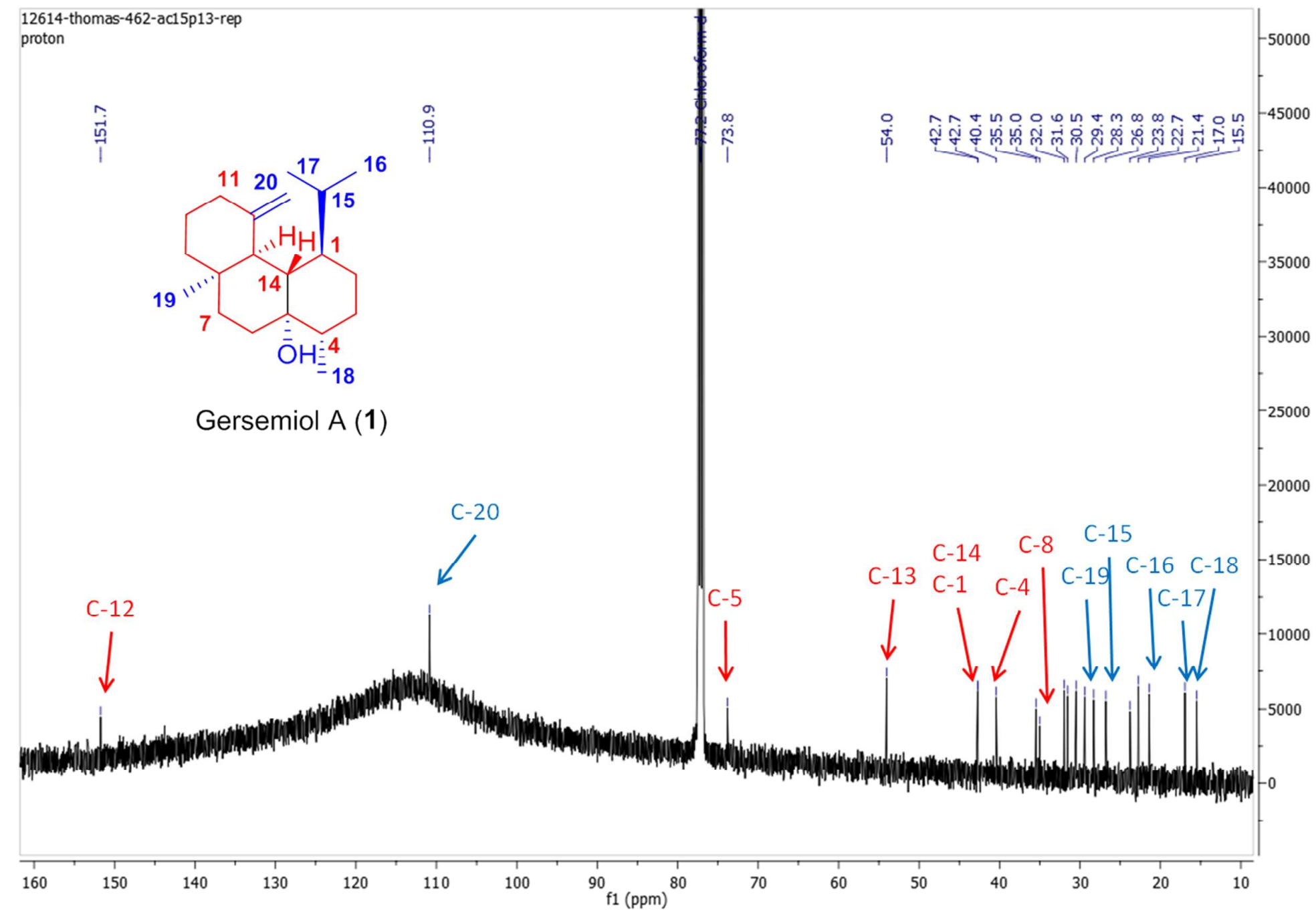

${ }^{13} \mathrm{C}$ NMR spectrum of 1 at $125 \mathrm{MHz}$ in $\mathrm{CDCl}_{3}$ 


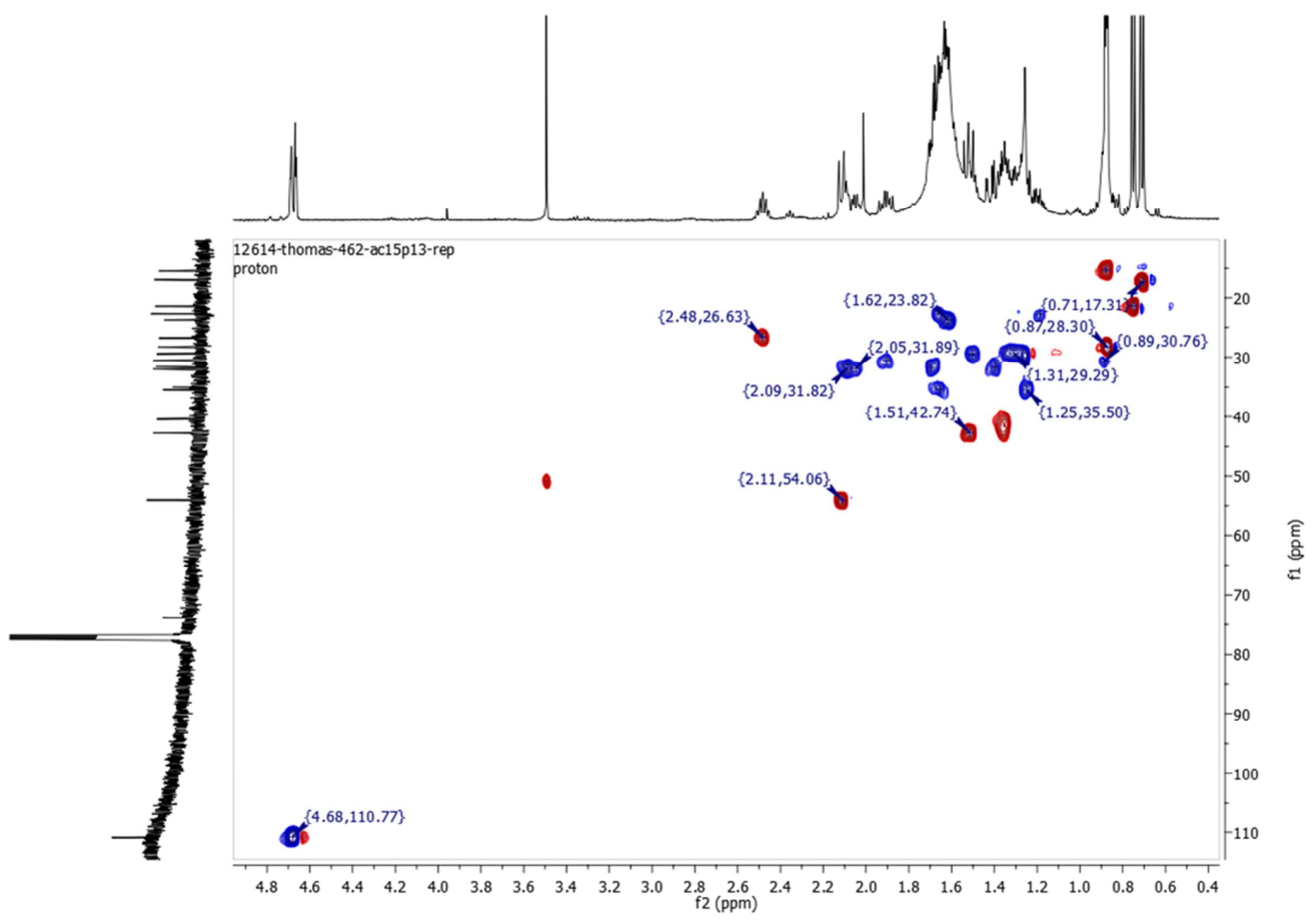

HSQC NMR spectrum of 1 at $500 \mathrm{MHz}$ in $\mathrm{CDCl}_{3}$ 


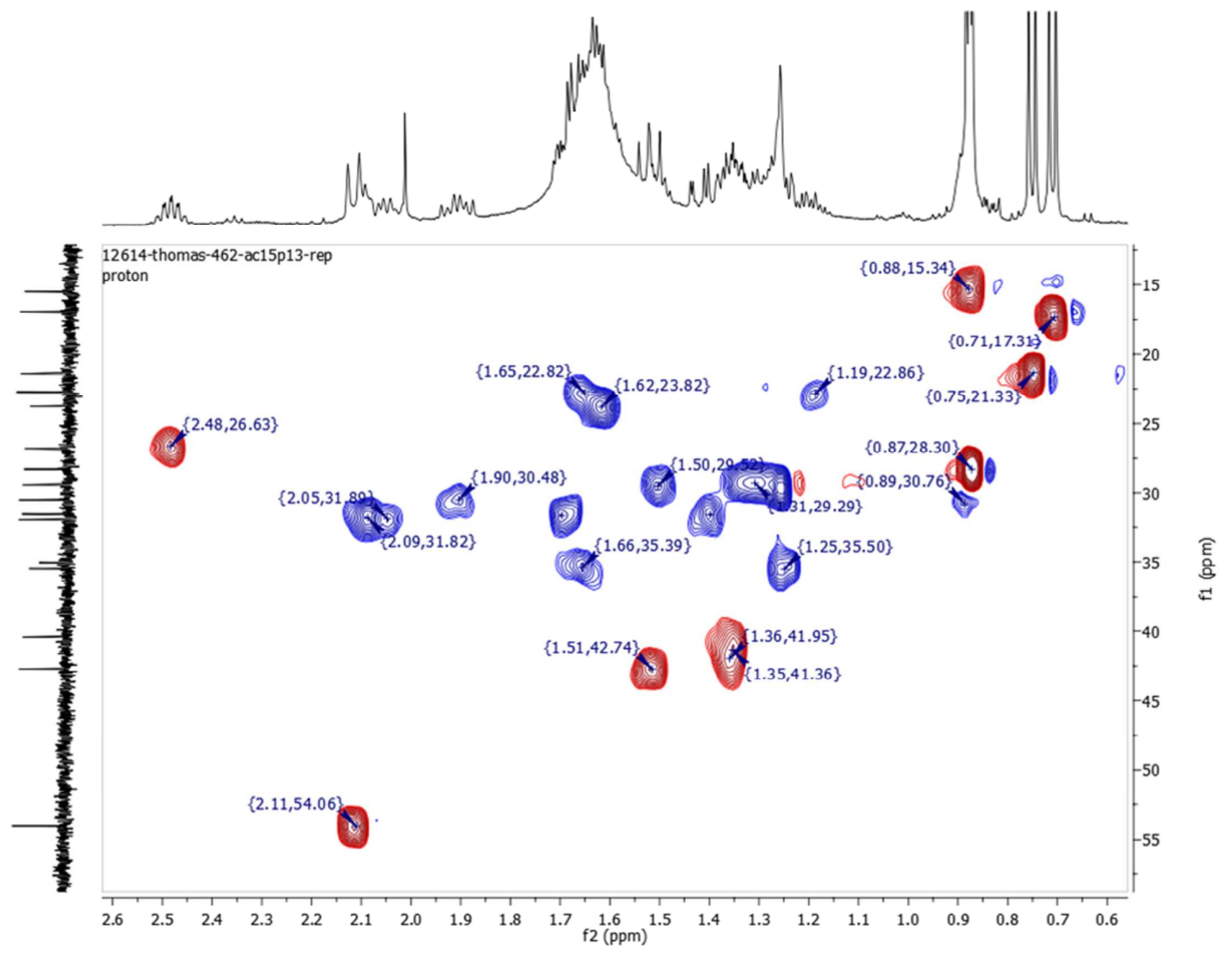

Expansion of $\mathrm{HSQC}$ NMR spectrum of $\mathbf{1}$ at $500 \mathrm{MHz}$ in $\mathrm{CDCl}_{3}$ 


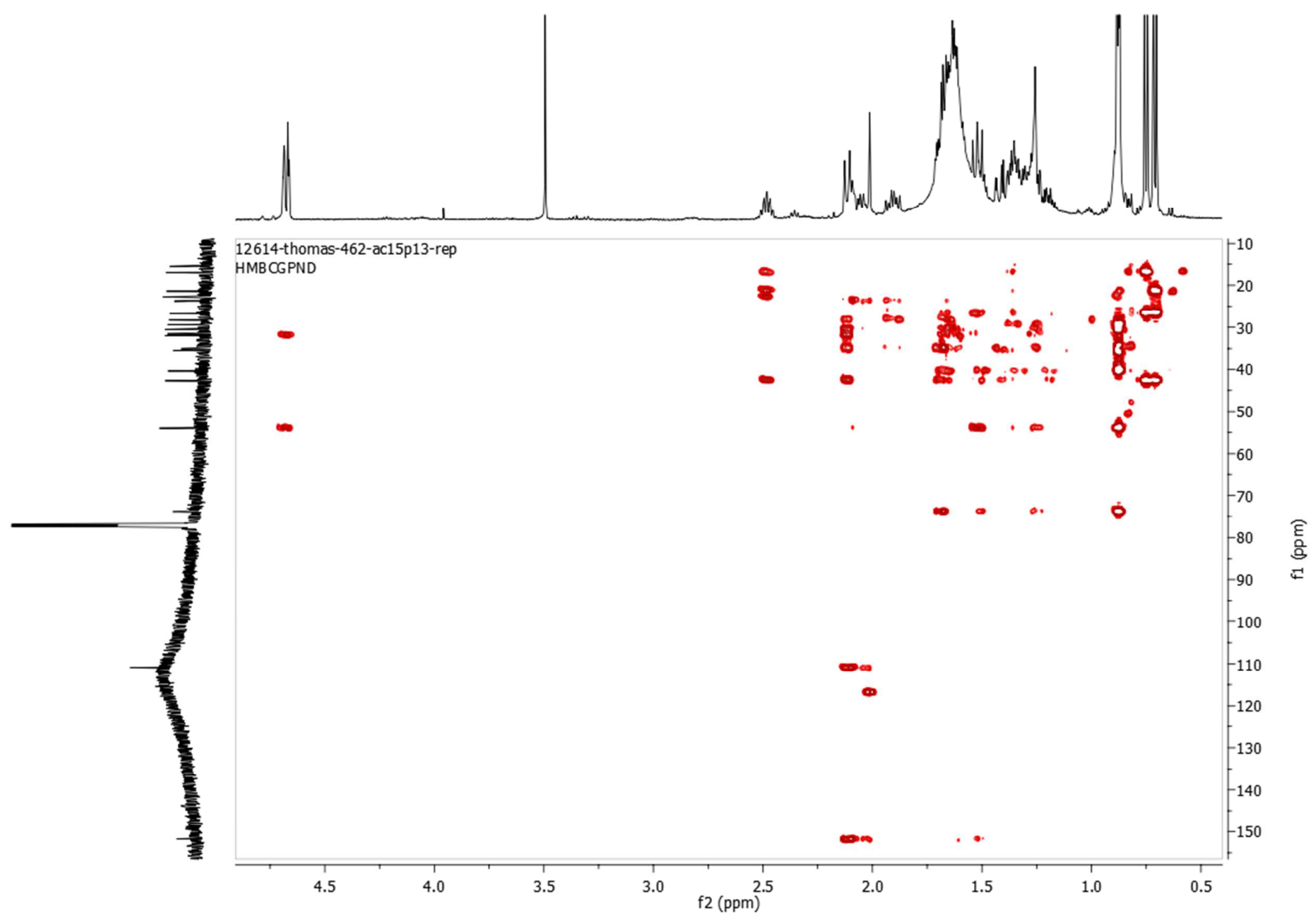

$\mathrm{HMBC}$ spectrum of 1 at $500 \mathrm{MHz}$ in $\mathrm{CDCl}_{3}$ 


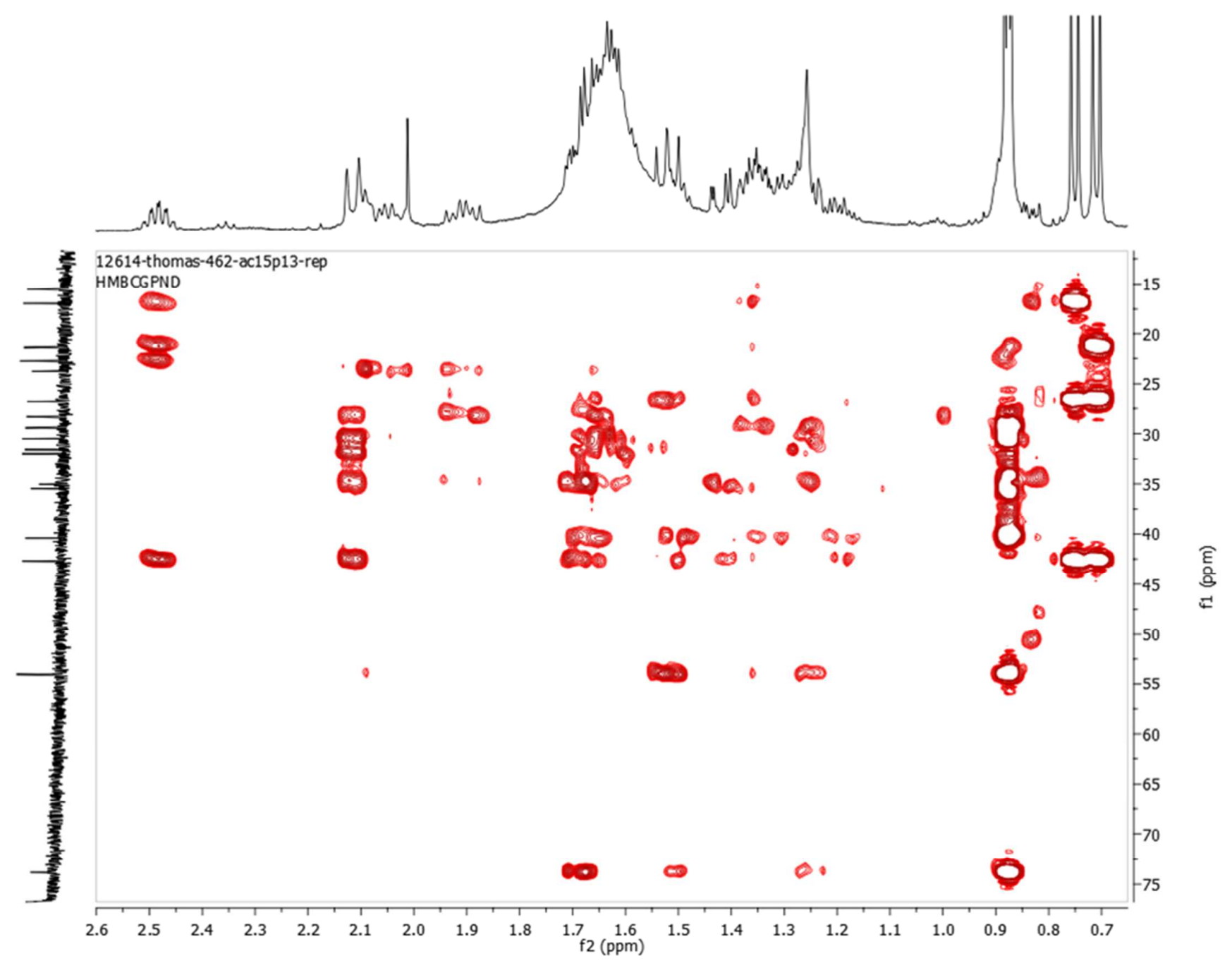

Expansion of $\mathrm{HMBC}$ spectrum of 1 at $500 \mathrm{MHz}$ in $\mathrm{CDCl}_{3}$ 


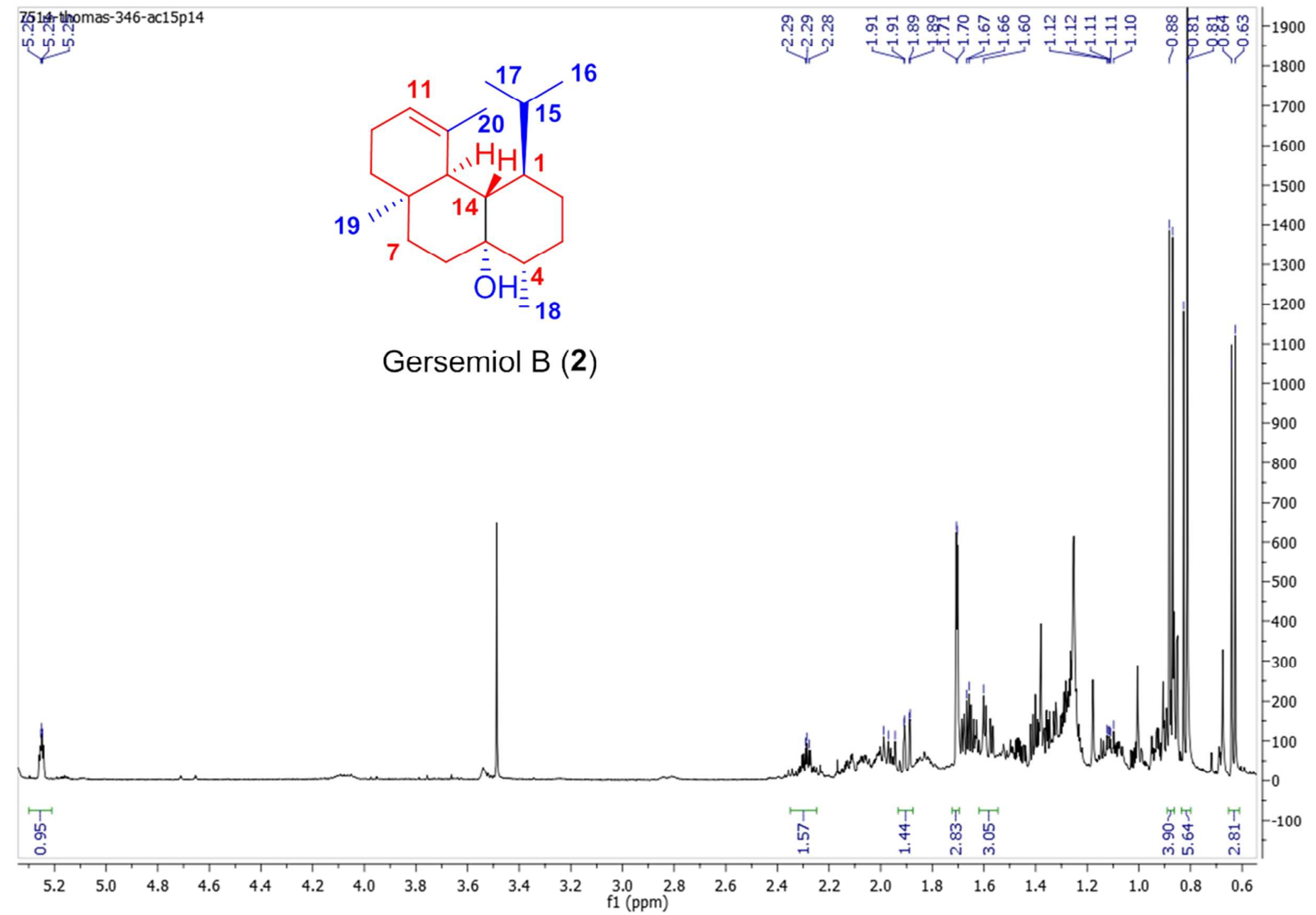

${ }^{1} \mathrm{H}$ NMR spectrum of 2 at $500 \mathrm{MHz}$ in $\mathrm{CDCl}_{3}$ 


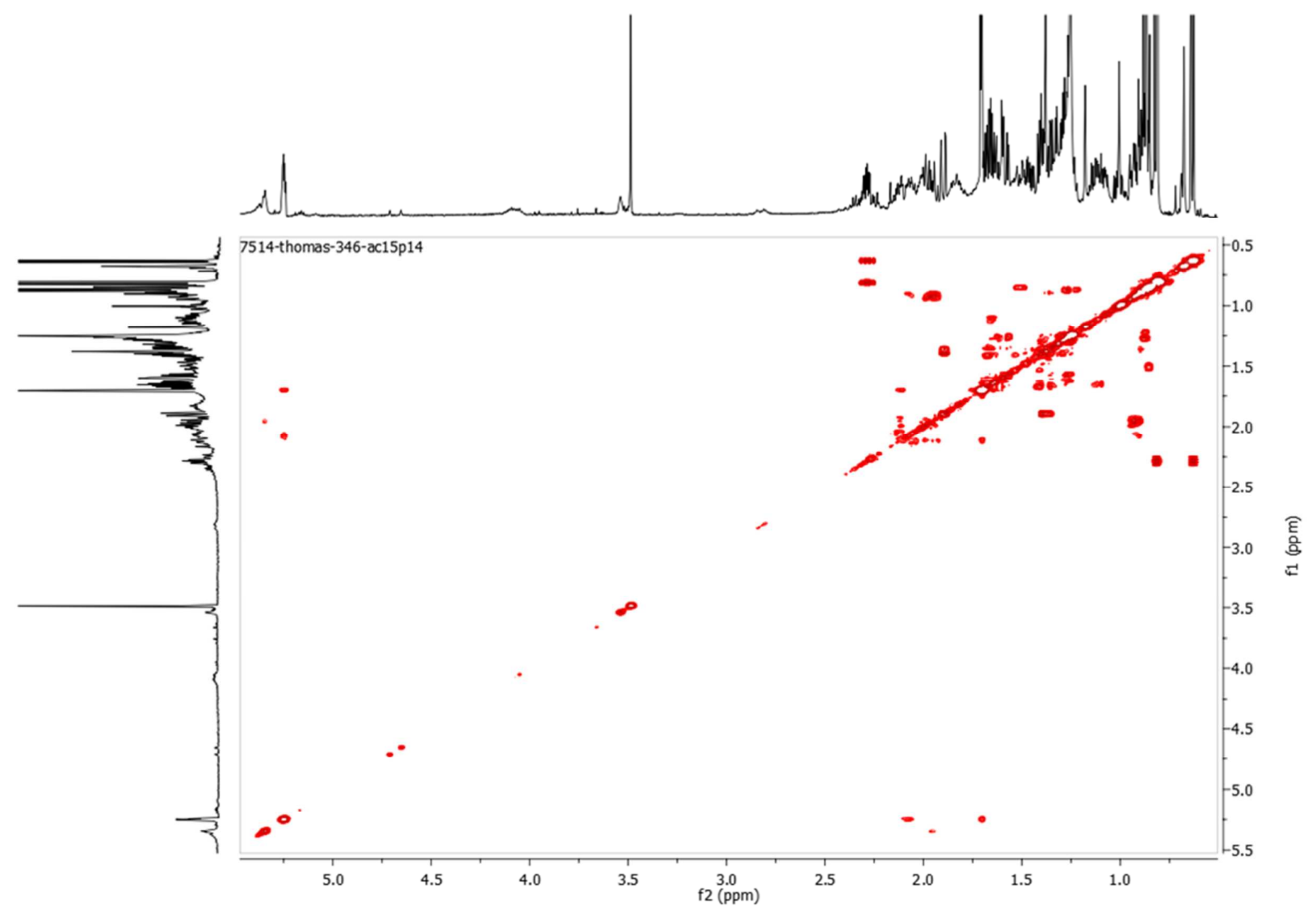

COSY NMR spectrum of $\mathbf{2}$ at $500 \mathrm{MHz}$ in $\mathrm{CDCl}_{3}$ 


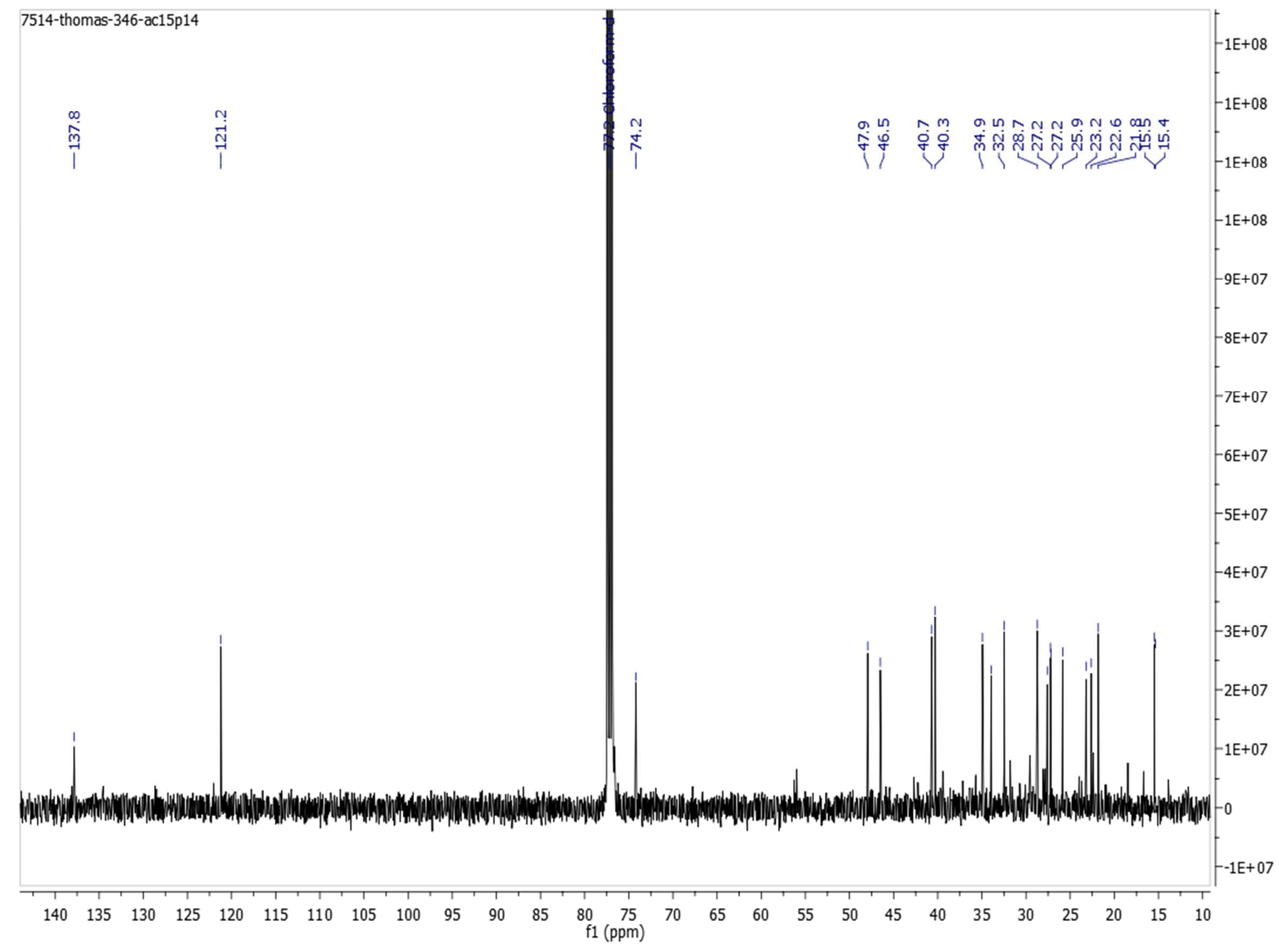

${ }^{13} \mathrm{C}$ NMR spectrum of 2 at $125 \mathrm{MHz}$ in $\mathrm{CDCl}_{3}$ 


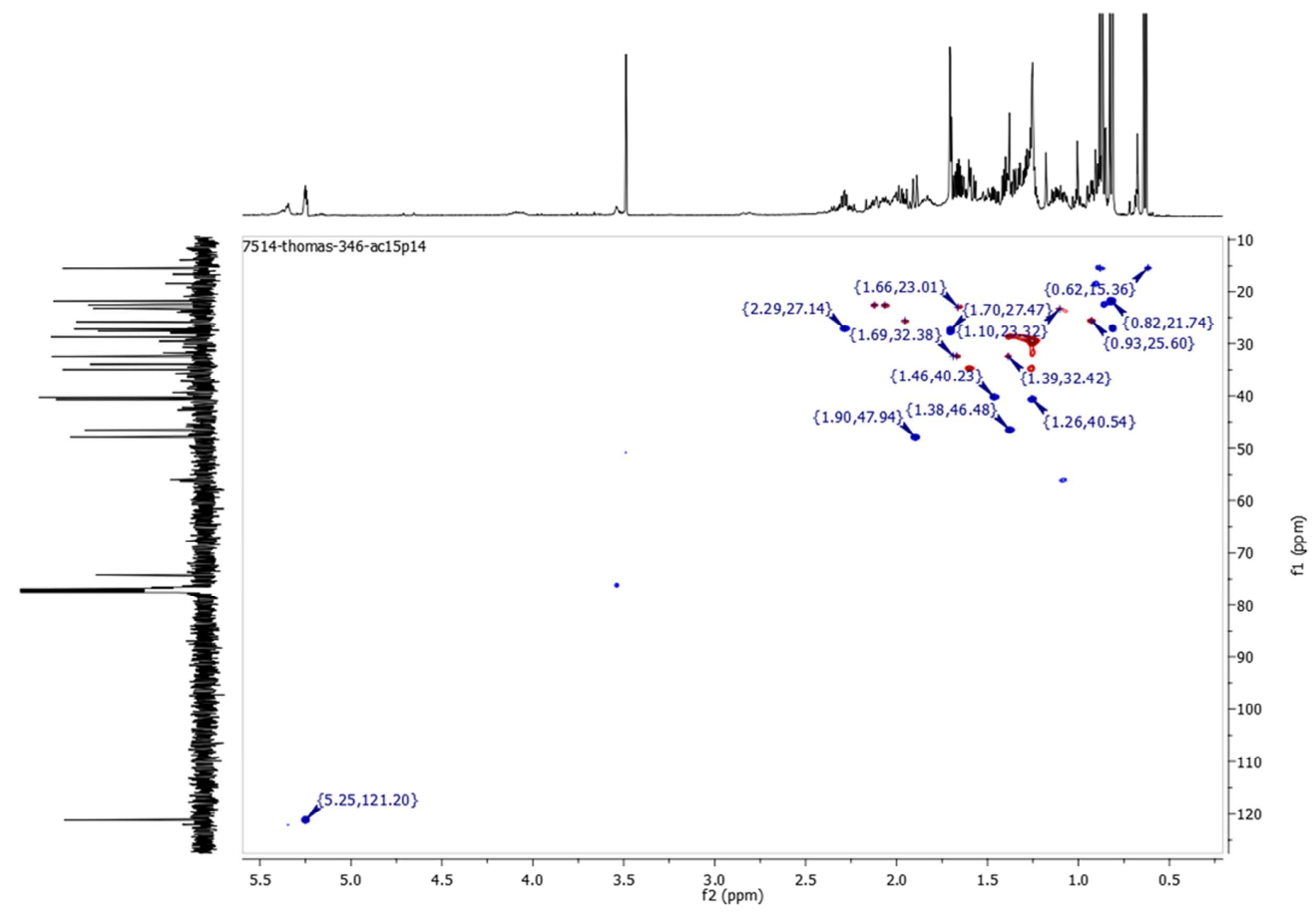

HSQC NMR spectrum of 2 at $500 \mathrm{MHz}$ in $\mathrm{CDCl}_{3}$ 


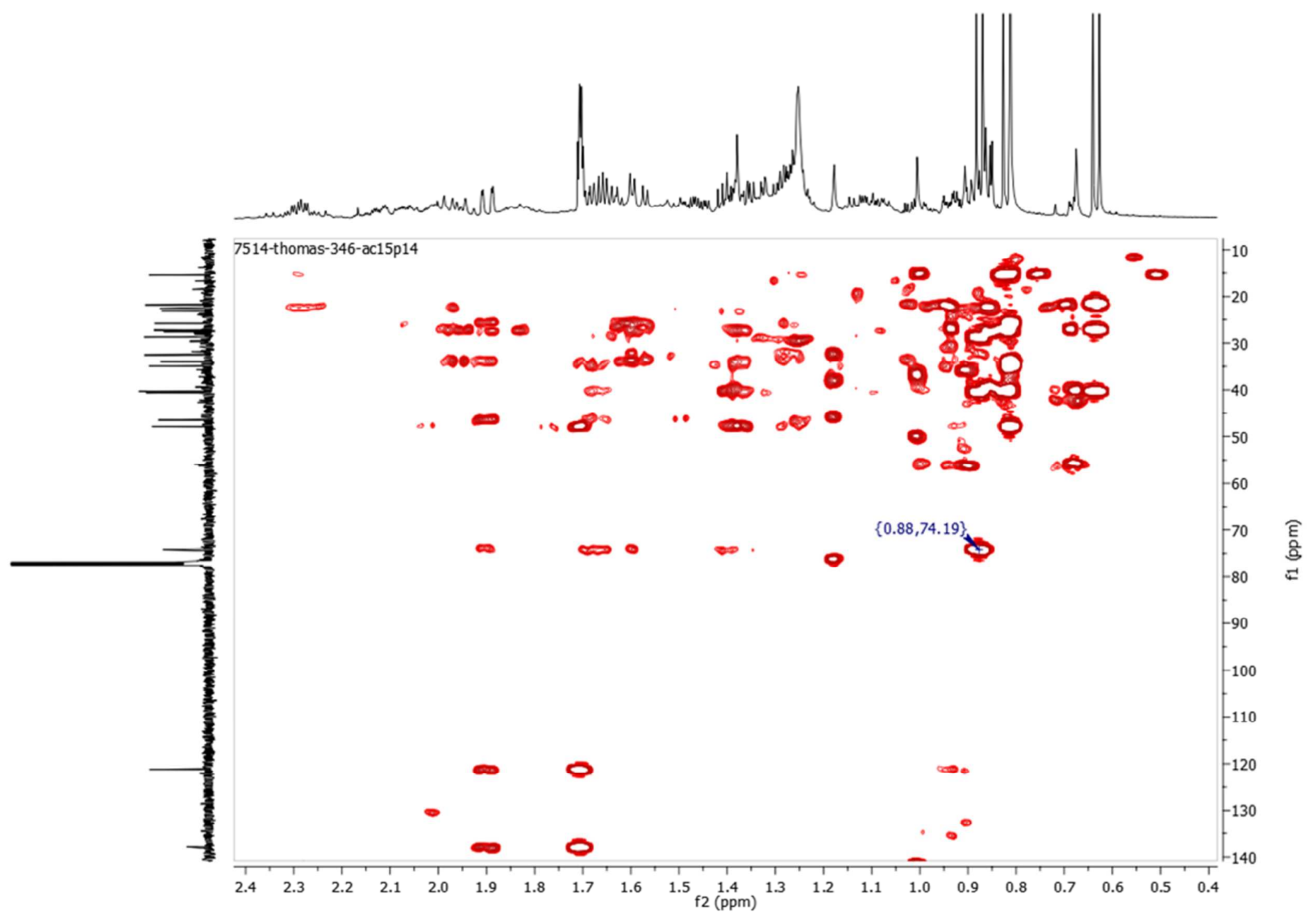

$\mathrm{HMBC}$ NMR spectrum of $\mathbf{2}$ at $500 \mathrm{MHz}$ in $\mathrm{CDCl}_{3}$ 


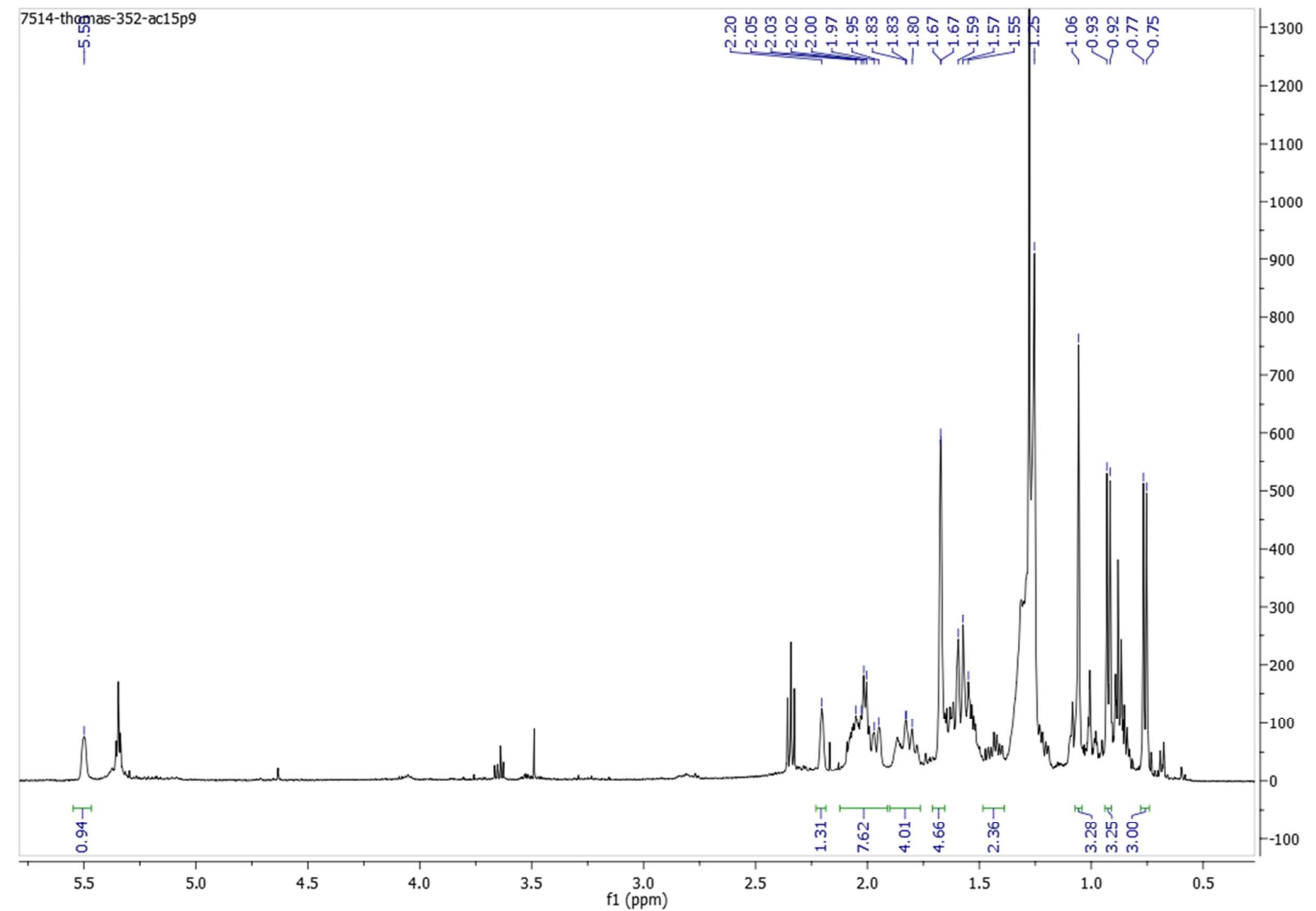

${ }^{1} \mathrm{H} \mathrm{NMR}$ spectrum of 3 at $500 \mathrm{MHz}$ in $\mathrm{CDCl}_{3}$ 


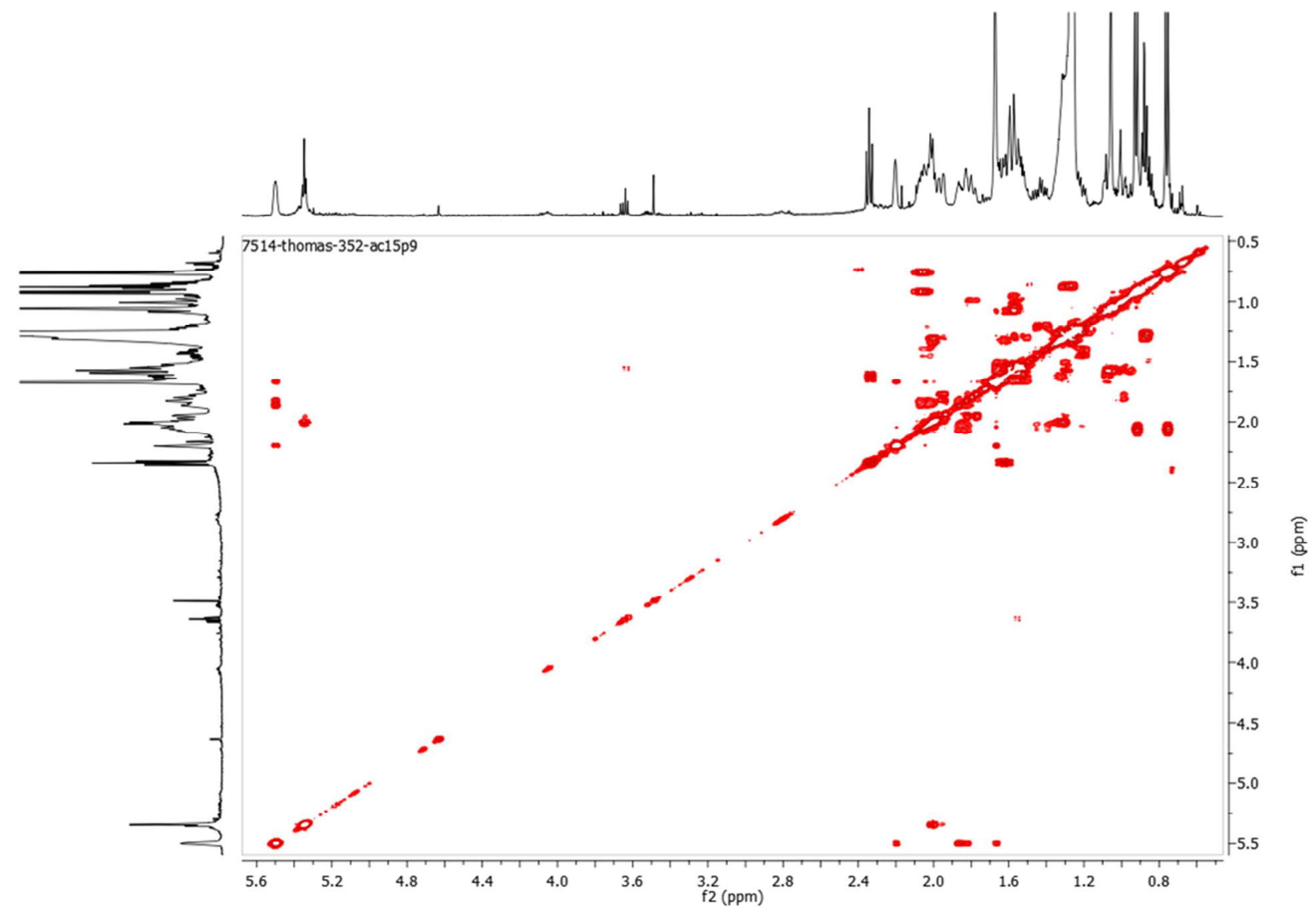

COSY NMR spectrum of $\mathbf{3}$ at $500 \mathrm{MHz}$ in $\mathrm{CDCl}_{3}$ 


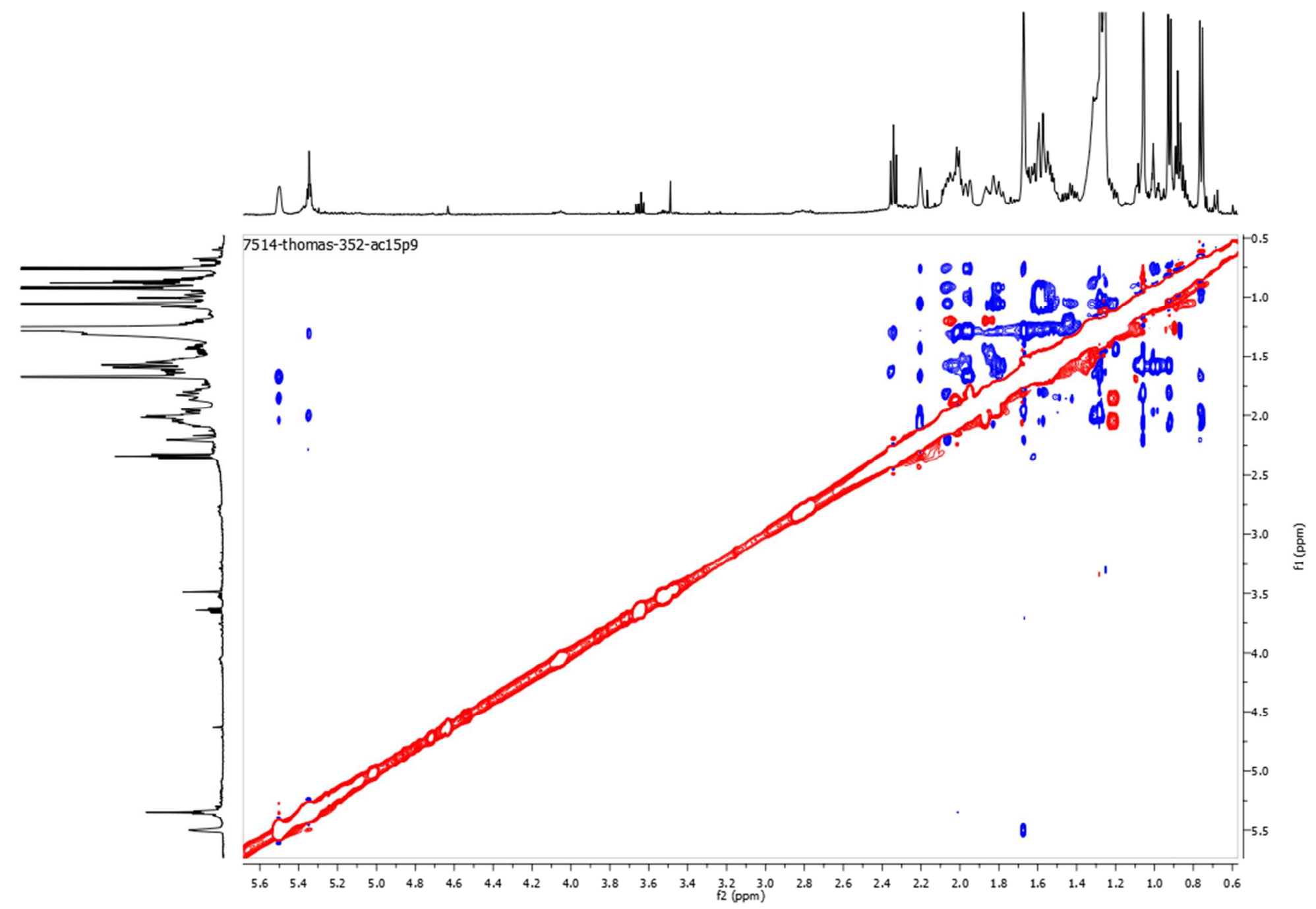

NOESY NMR spectrum of 3 at $500 \mathrm{MHz}$ in $\mathrm{CDCl}_{3}$ 


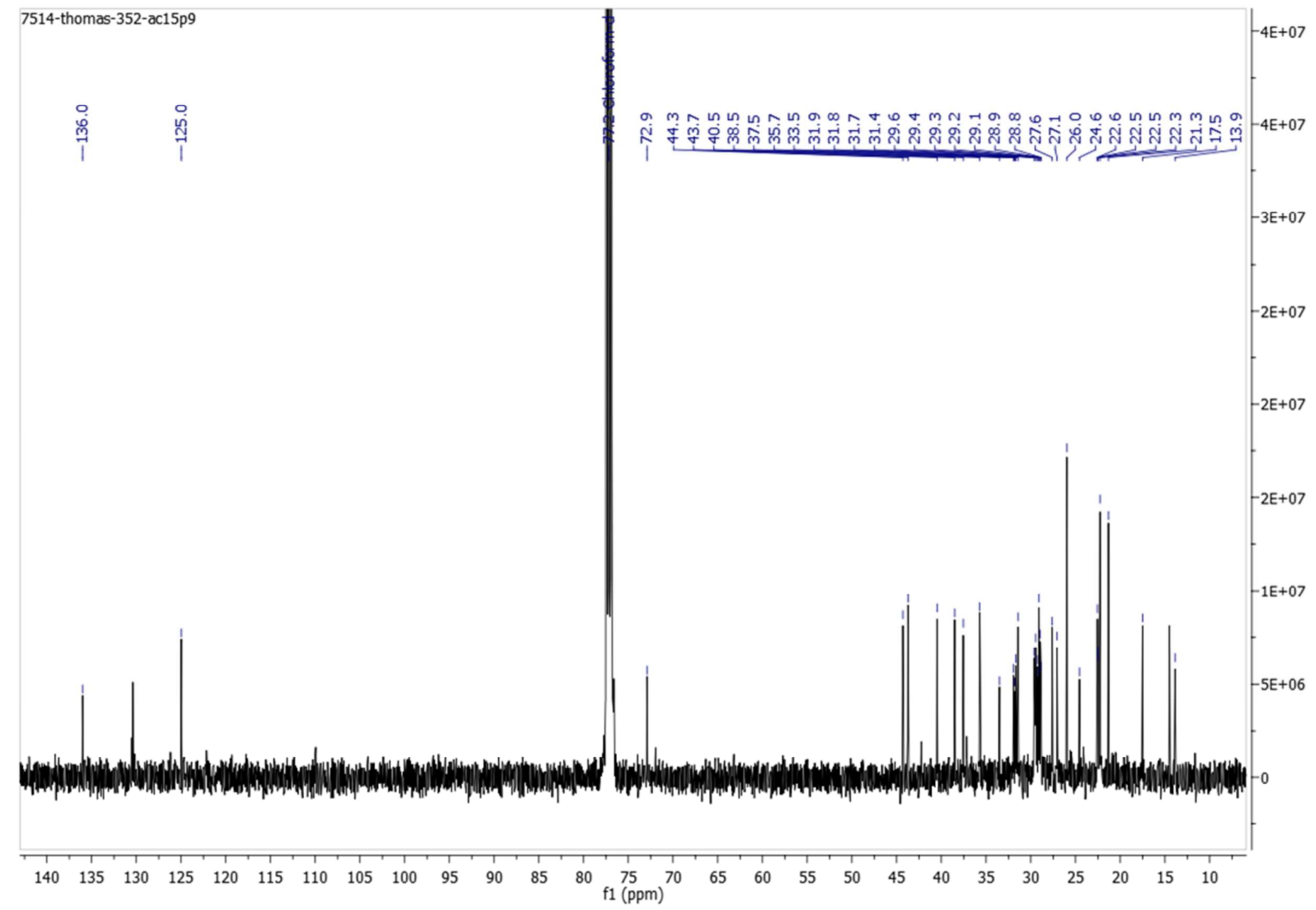

${ }^{13} \mathrm{C}$ NMR spectrum of 3 at $125 \mathrm{MHz}$ in $\mathrm{CDCl}_{3}$ 


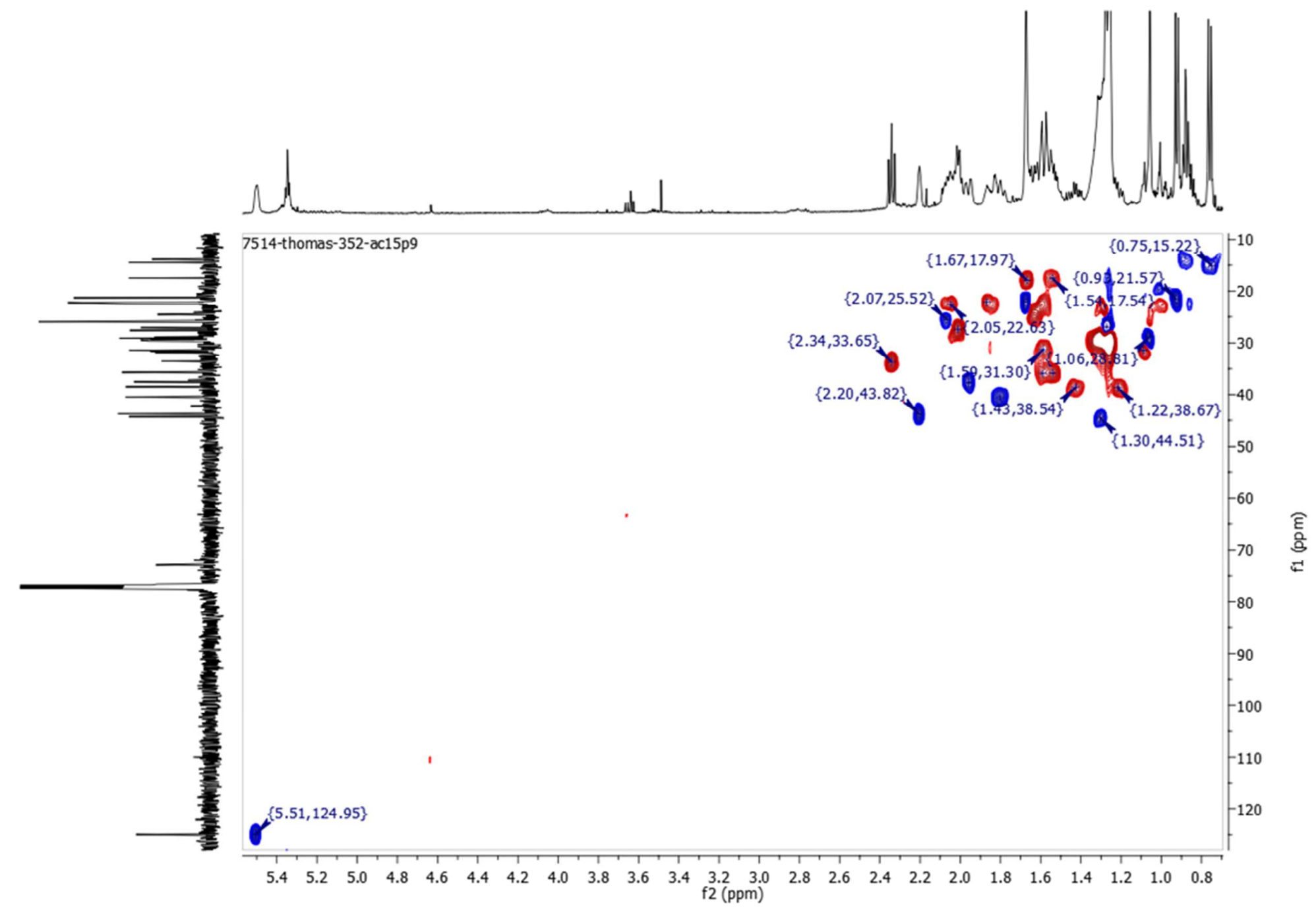

HSQC NMR spectrum of $\mathbf{3}$ at $500 \mathrm{MHz}$ in $\mathrm{CDCl}_{3}$ 


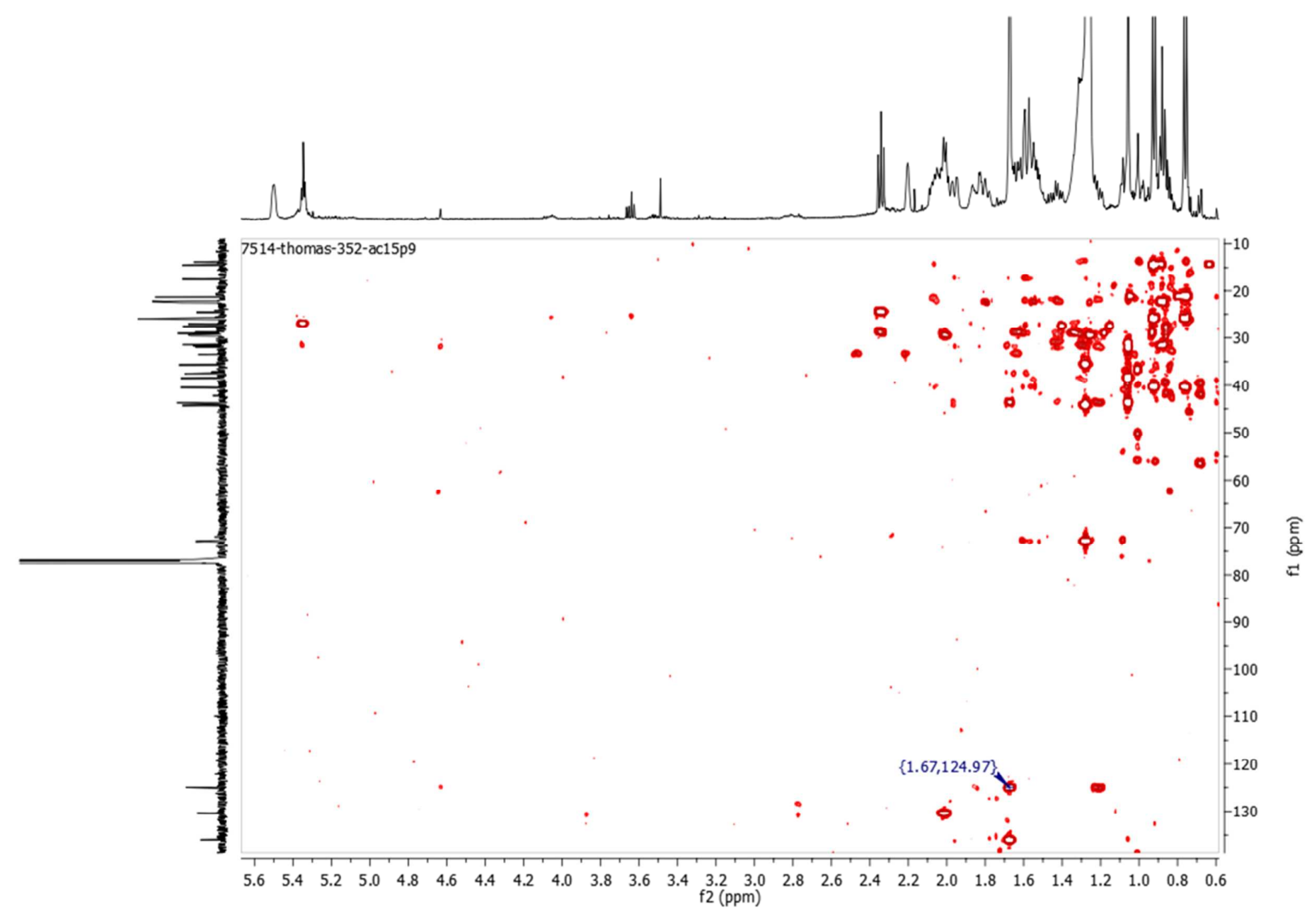

HMBC NMR spectrum of 3 at $500 \mathrm{MHz}$ in $\mathrm{CDCl}_{3}$ 


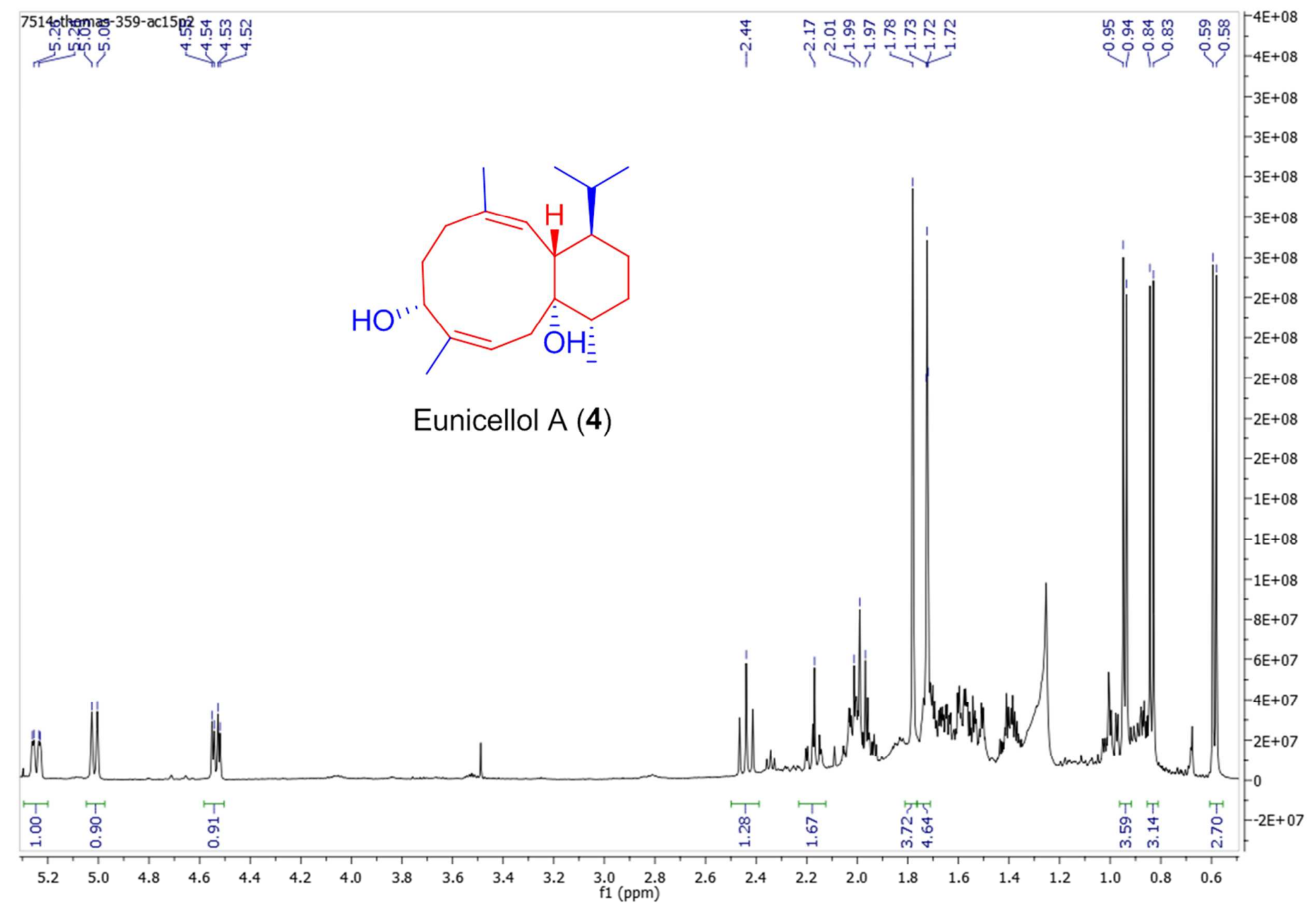

${ }^{1} \mathrm{H}$ NMR spectrum of 4 at $500 \mathrm{MHz}$ in $\mathrm{CDCl}_{3}$ 


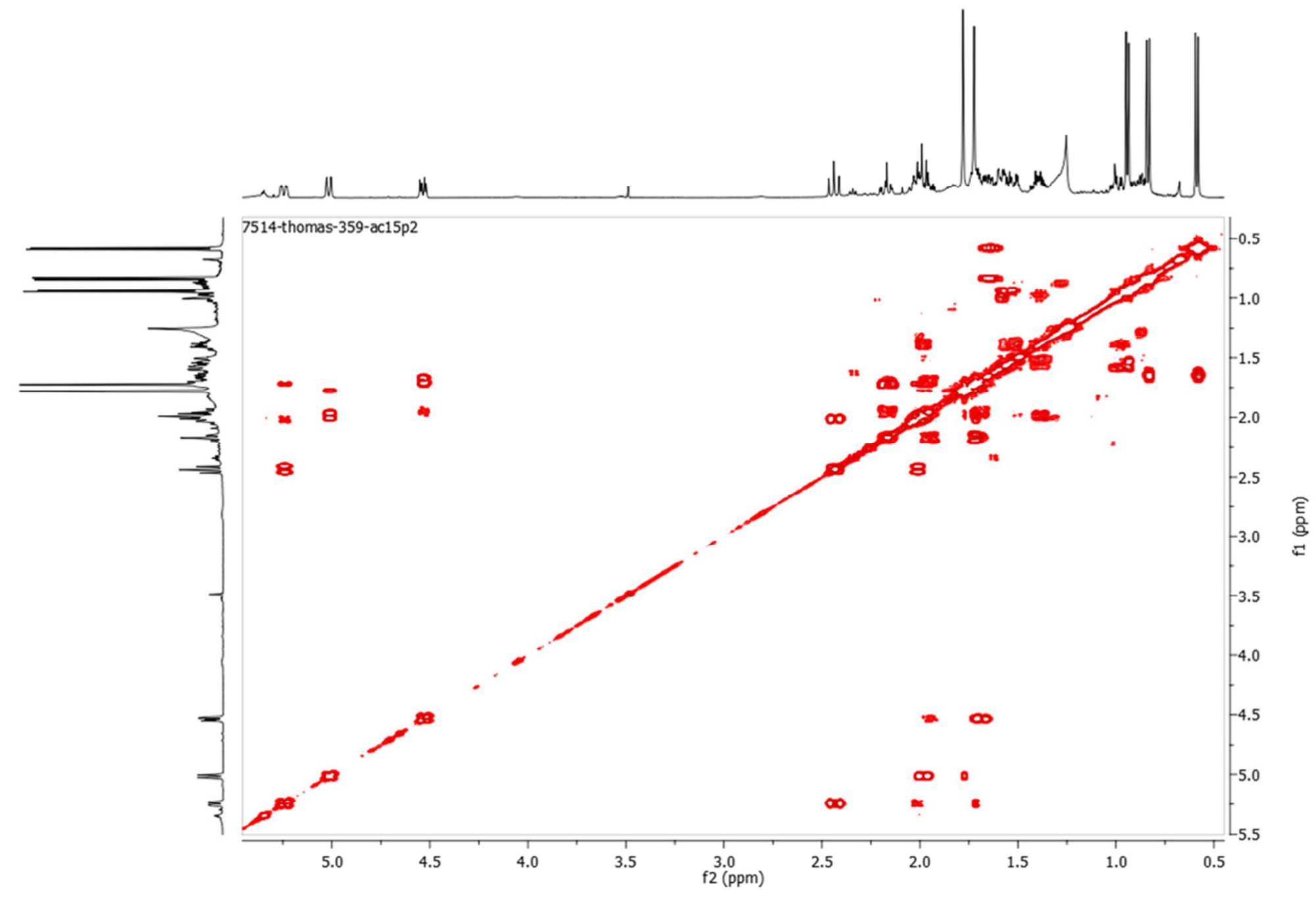

COSY NMR spectrum of $\mathbf{4}$ at $500 \mathrm{MHz}$ in $\mathrm{CDCl}_{3}$ 


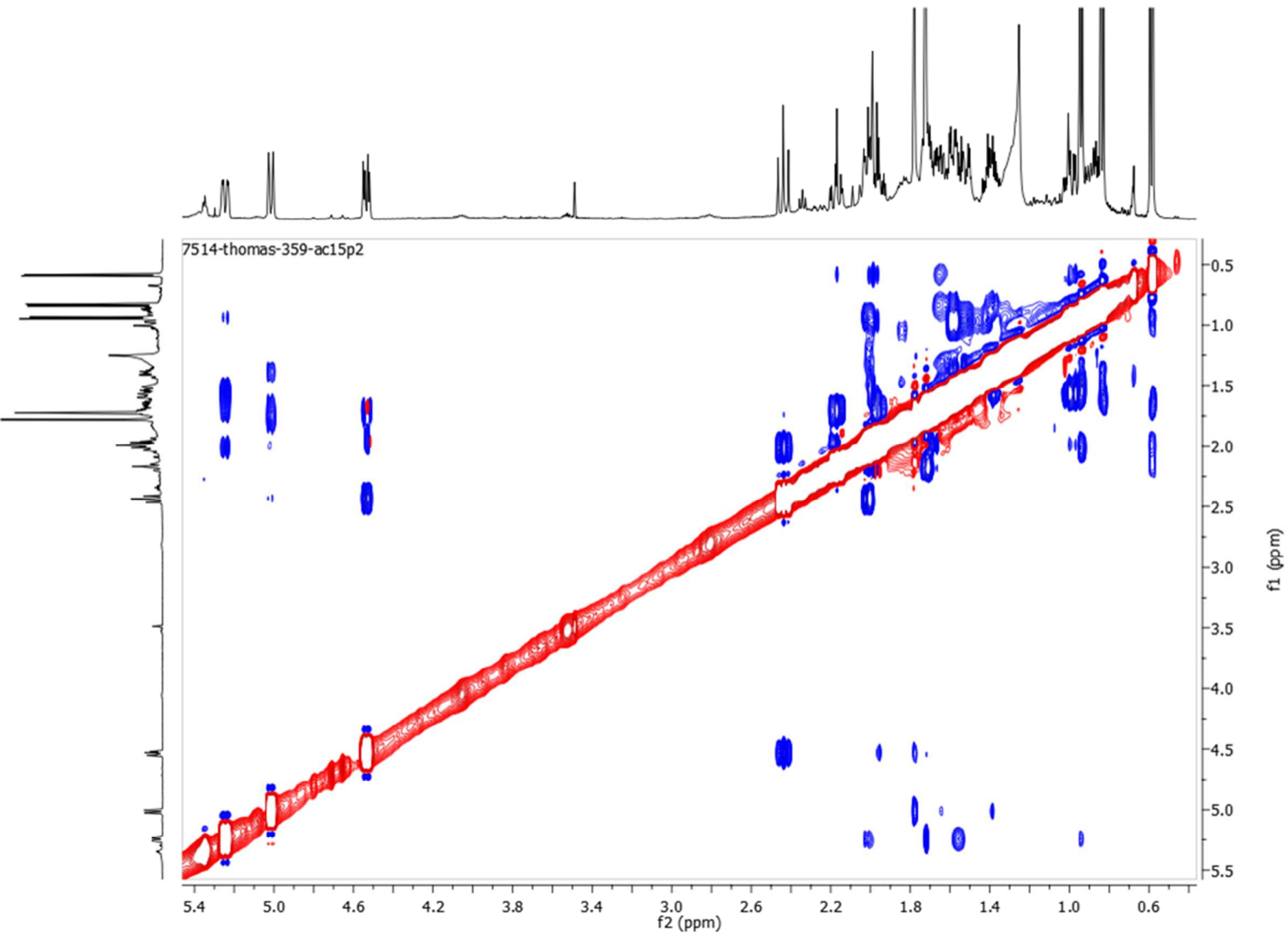

NOESY NMR spectrum of 4 at $500 \mathrm{MHz}$ in $\mathrm{CDCl}_{3}$ 


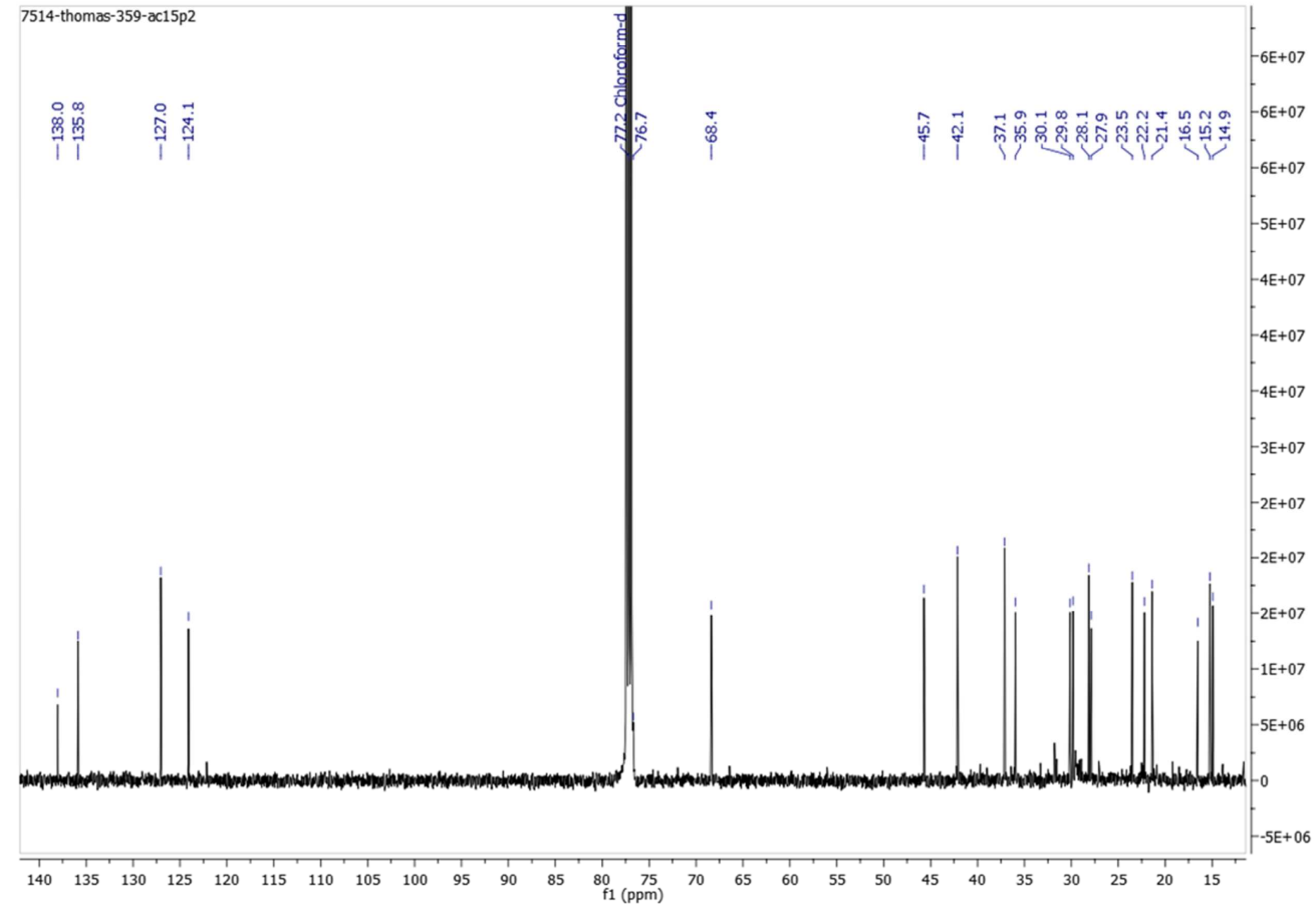

${ }^{13} \mathrm{C}$ NMR spectrum of 4 at $125 \mathrm{MHz}$ in $\mathrm{CDCl}_{3}$ 


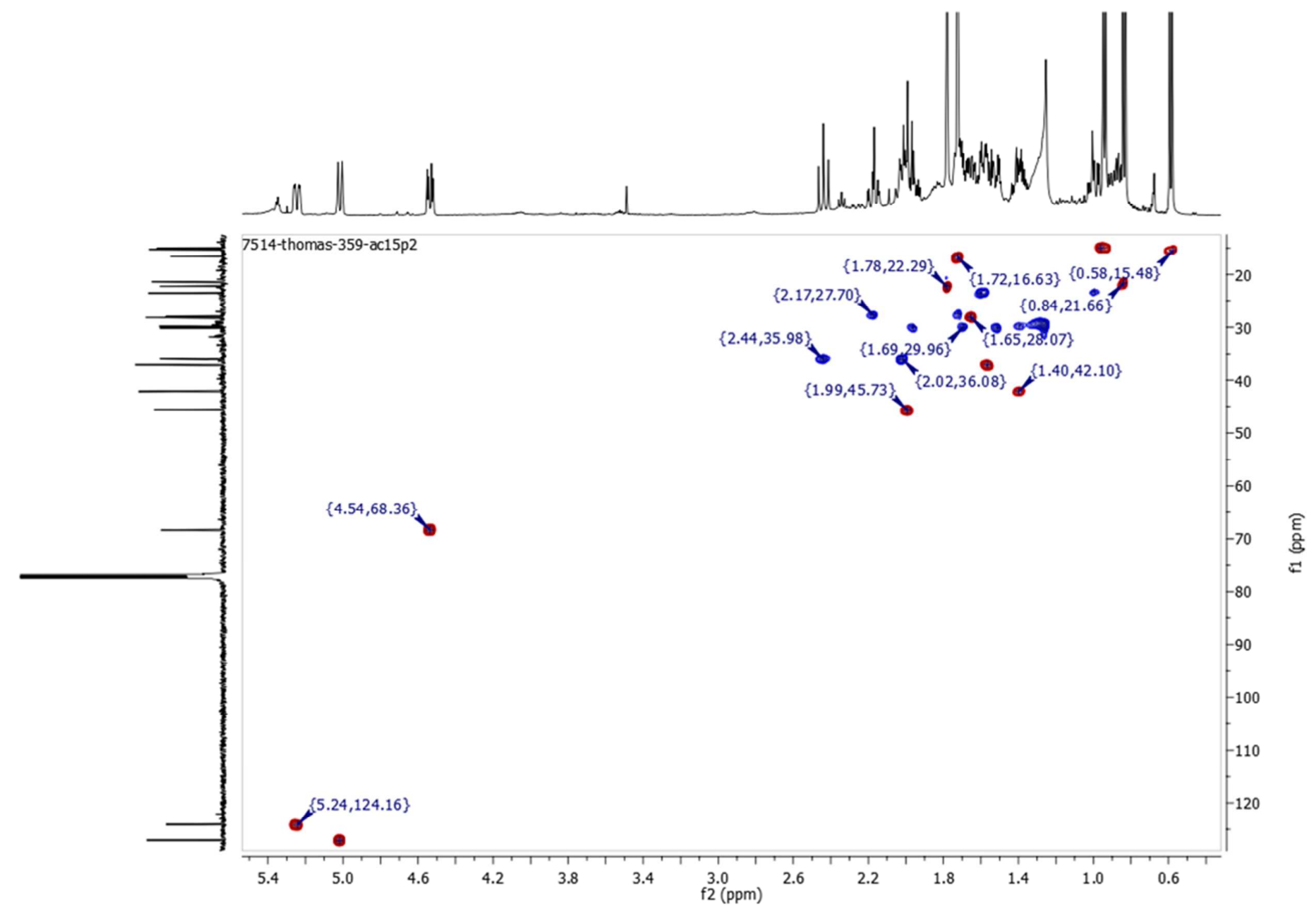

HSQC NMR spectrum of $\mathbf{4}$ at $500 \mathrm{MHz}$ in $\mathrm{CDCl}_{3}$ 


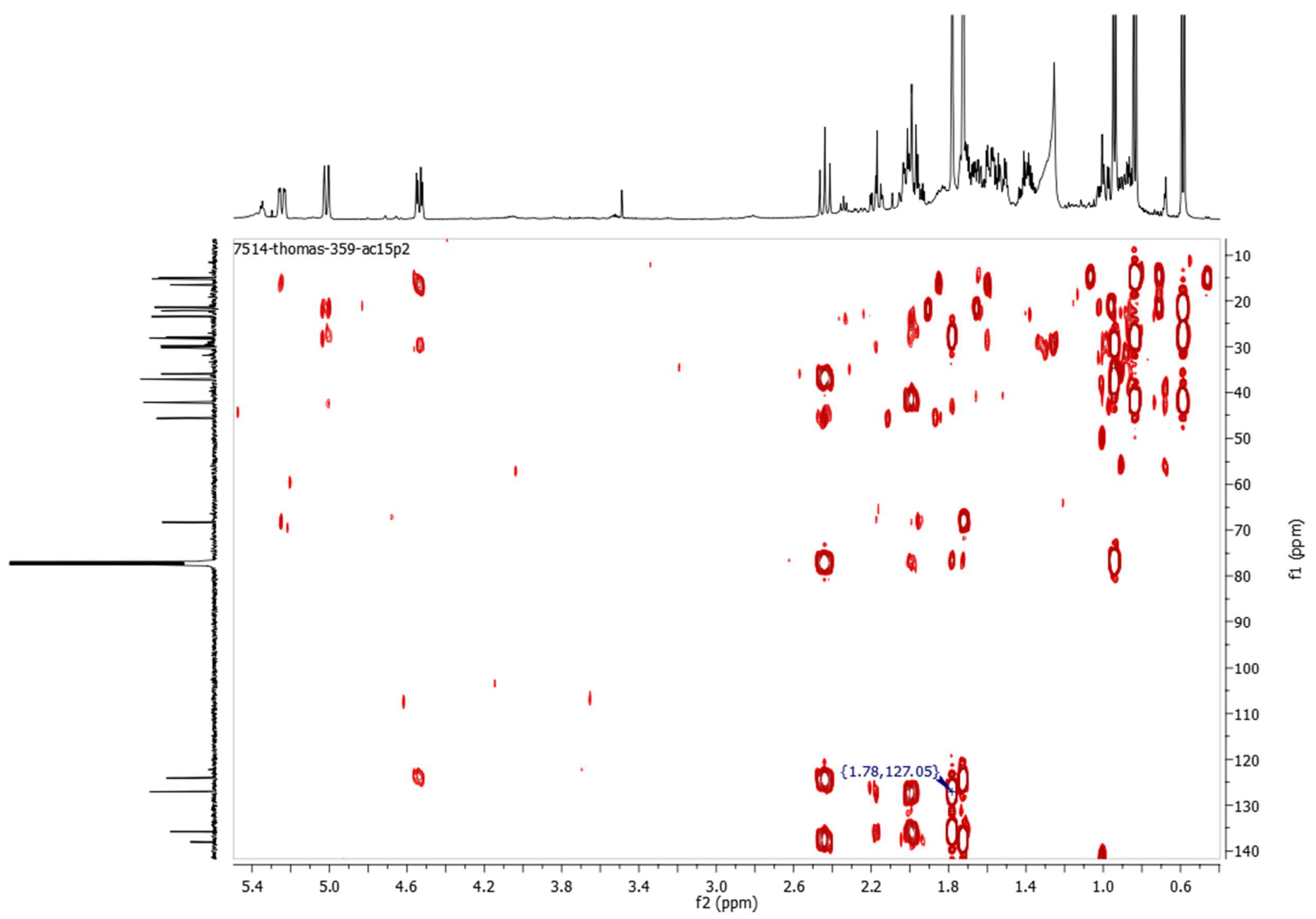

$\mathrm{HMBC}$ NMR spectrum of 4 at $500 \mathrm{MHz}$ in $\mathrm{CDCl}_{3}$ 


\section{Computational Methods}

Theoretical values were assessed for the 4 more stable conformers of the 4 diastereoisomers at C- 4 and $\mathrm{C}-5$.

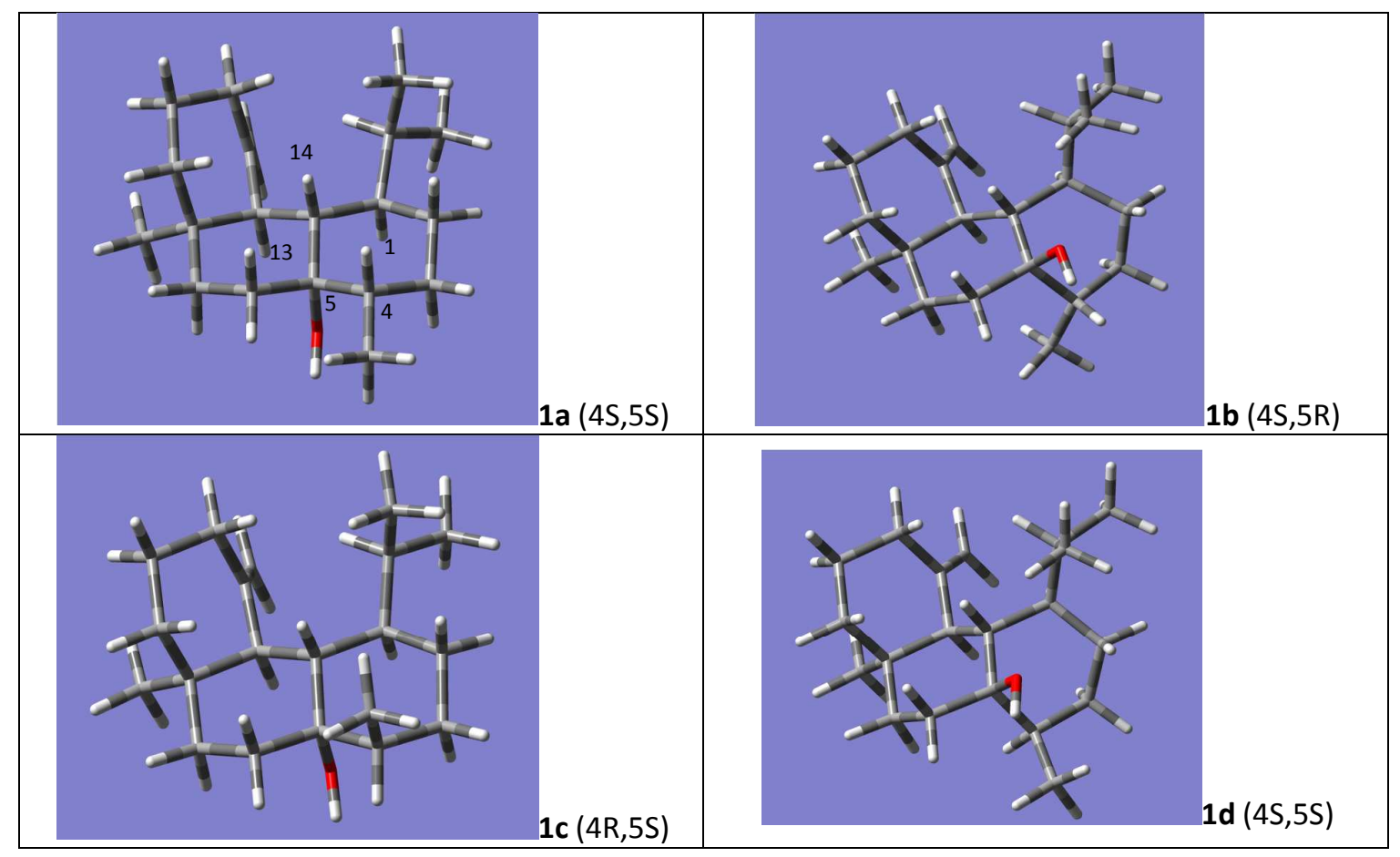

Tableau 1: DFT calculated ${ }^{1} \mathrm{H}$ coupling constants for 4 diasteroisomers of compound 1.

\begin{tabular}{ccc}
\hline structure \# & ${ }^{3} J_{\mathrm{H} 13-\mathrm{H} 14}$ & ${ }^{3} \mathrm{~J}_{\mathrm{H} 14-\mathrm{H} 1}$ \\
\hline $\mathbf{1} \exp$ & 11 & 9.5 \\
$\mathbf{1 a}$ & 8.91 & 8.93 \\
$\mathbf{1 b}$ & 10.84 & 3.9 \\
$\mathbf{1 c}$ & 8.86 & 8.65 \\
$\mathbf{1 d}$ & 10.5 & 2.72 \\
\hline
\end{tabular}




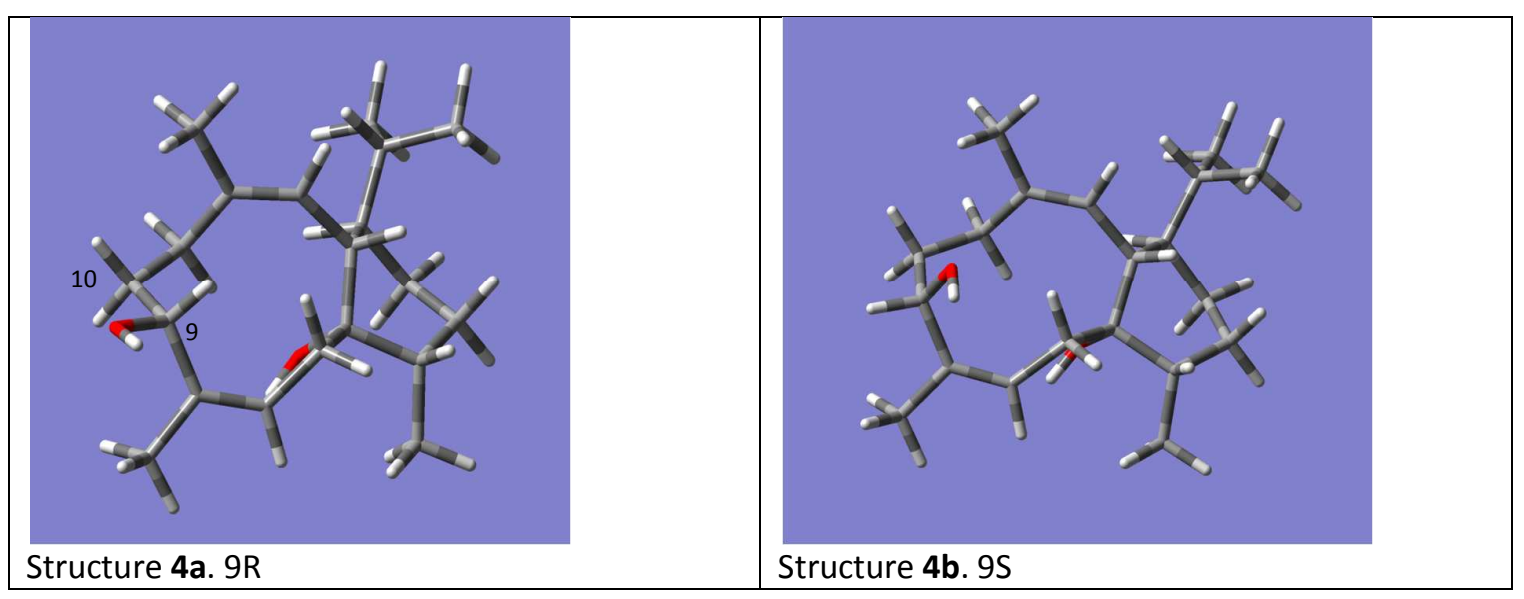

Tableau 2: DFT calculated ${ }^{1} \mathrm{H}$ coupling constants for both diastereoisomers of compound 4.

\begin{tabular}{cc}
\hline structure \# & ${ }^{3} J_{\mathrm{H} 9-\mathrm{H} 10}$ \\
\hline $\mathbf{4}$ exp & $12.0,4.5$ \\
4a & $9.6,1.9$ \\
4b & $4.6,2.9$ \\
\hline
\end{tabular}

